\title{
Nanotechnology: An Untapped Resource for Food Packaging
}

\author{
Chetan Sharma ${ }^{1 \star t}$, Romika Dhiman ${ }^{2 \dagger}$, Namita Rokana ${ }^{1}$ and Harsh Panwar ${ }^{1}$ \\ ${ }^{1}$ Department of Dairy Microbiology, College of Dairy Science and Technology, Guru Angad Dev Veterinary and Animal \\ Sciences University, Ludhiana, India, ${ }^{2}$ Department of Microbiology, D.A.V. College for Girls, Yamuna Nagar, India
}

OPEN ACCESS

Edited by:

Rosalba Lanciotti,

Università di Bologna, Italy

Reviewed by:

Leda Giannuzzi,

National University of La Plata,

Argentina

Francesca Patrignani,

Università di Bologna, Italy

*Correspondence:

Chetan Sharma

chetanmicro147@gmail.com

${ }^{\dagger}$ These authors have contributed equally to this work.

Specialty section:

This article was submitted to

Food Microbiology,

a section of the journal

Frontiers in Microbiology

Received: 17 November 2016

Accepted: 25 August 2017

Published: 12 September 2017

Citation:

Sharma C, Dhiman R, Rokana N and Panwar H (2017) Nanotechnology: An Untapped Resource for Food

Packaging. Front. Microbiol. 8:1735.

doi: 10.3389/fmicb.2017.01735
Food commodities are packaged and hygienically transported to protect and preserve them from any un-acceptable alteration in quality, before reaching the end-consumer. Food packaging continues to evolve along-with the innovations in material science and technology, as well as in light of consumer's demand. Presently, the modern consumers of competitive economies demands for food with natural quality, assured safety, minimal processing, extended shelf-life and ready-to-eat concept. Innovative packaging systems, not only ascertains transit preservation and effective distribution, but also facilitates communication at the consumer levels. The technological advances in the domain of food packaging in twenty-first century are mainly chaired by nanotechnology, the science of nano-materials. Nanotechnology manipulates and creates nanometer scale materials, of commercial and scientific relevance. Introduction of nanotechnology in food packaging sector has significantly addressed the food quality, safety and stability concerns. Besides, nanotechnology based packaging intimate's consumers about the real time quality of food product. Additionally, nanotechnology has been explored for controlled release of preservatives/antimicrobials, extending the product shelf life within the package. The promising reports for nanotechnology interventions in food packaging have established this as an independent priority research area. Nanoparticles based food packages offer improved barrier and mechanical properties, along with food preservation and have gained welcoming response from market and end users. In contrary, recent advances and up-liftment in this area have raised various ethical, environmental and safety concerns. Policies and regulation regarding nanoparticles incorporation in food packaging are being reviewed. This review presents the existing knowledge, recent advances, concerns and future applications of nanotechnology in food packaging sector.

Keywords: nanotechnology, packaging, nanoparticles, antimicrobial, nanosensors

\section{INTRODUCTION}

Global food industry is under rising pressure to meet consumers demand for safe, healthy and fresh food, along with a challenge to meet updated strict food safety regulations. Awareness through easy access to digital media have motivated consumer toward demand for fresh, minimally processed, nutritious, safe and ready-to-eat food products with well-defined labels. In-order to make certain the safety and authenticity of food stuffs throughout the food supply chain, food manufacturers, traders, buyers and food regulatory authorities seeks a novel, cost-effective, fast and consistent tool to monitor the packaged food quality; more effectively to the traditional passive barrier concept, as 
packaging is a crucial component of every segment of food industry (Janjarasskul and Suppakul, 2016; Sarkar et al., 2017). Nano-technological interventions to food packaging chiefly explore three possibilities viz. direct incorporation into food products, incorporation in food packaging material, and application in food processing. The commercialization, successful execution and responses to diverse applications of nanotechnology are determined by the consumer's outlook toward and acceptance of newly introduced technologies and their applications (Gupta et al., 2011; Kim et al., 2014). Outcome from majority of the studies (apart from those of sample population) indicates wide consumer acceptance of nanoparticles as packaging materials and also when they are used during processing activities; as compared to their direct incorporation into agri-food products (Giles et al., 2015).

The concept of nanotechnology was introduced in 1959 by Richard Feynman and the term "nanotechnology" was later coined by Norio Taniguchi in 1974. Nanotechnology mainly comprises of fabrication, characterization and manipulation of nano-range $(<100 \mathrm{~nm})$ molecules. The application of nanotechnology in polymers involve the design, manufacturing, processing and application of polymer materials filled with nano-particles and/or devices of nano range (Paul and Robeson, 2008; Danie et al., 2013; Momin and Joshi, 2015). The enormous potential of this promising intervention has gained attention of researchers from multi-disciplinary areas i.e., biological sciences, chemistry, engineering and physics. Owing to high global interest, nanotechnology has been proposed to impact the global economy by around $\$ 3$ trillion by 2020, generating a requirement of approximately 6 million professionals in different inter-related sectors (Duncan, 2011). As predicted by the Institute for Health and Consumer Protection (IHPC), the nanoparticle based market will touch $\$ 20$ billion mark by 2020 (Belli, 2012; Montazer and Harifi, 2017). It can be anticipated that nanotechnology will create a major thrust for the development of advanced packaging systems for the sake of consumers. Differently from the materials at macroscale, nanomaterials display specific and improved physicochemical properties. By virtue of their small size, nanoparticles hold a huge surface-tovolume ratio and surface activity. When affixed to desirable polymers, nanomaterials results in improved mechanical strength, electrical conductivity and thermal stability etc. Nanomaterials thus improve the mechanical and barrier properties of food packages; along with offering active and intelligent packaging systems (Mihindukulasuriya and Lim, 2014).

In order to meet effective food packaging requirements, advanced nanomaterial augmented polymers will help to amplify the benefits associated with existing polymers, with enhanced safety, besides addressing environmental concerns. The developed packaging material will contribute in reducing any serious interaction between packaging and food matrices, impact over consumer's health, drop in quantity of waste material, improved biodegradability and barrier shielding to gases and light, and reduced $\mathrm{CO}_{2}$ emissions. The ongoing advancement(s) in the area of polymer nanomaterials for food packaging (PNFP) faces a challenge ahead to overcome the safety and regulatory barriers. Upon qualifying the safety parameters and production at a competitive ratio between cost and performance, the new PNFP will be an ideal candidate for widespread application in food packaging (Arora and Padua, 2010; Silvestre et al., 2011; Souza and Fernando, 2016).

The introduction of polymer nanotechnology in food packaging aims to improve the principal features of traditional packaging systems i.e., containment (ease of transportation and handling), convenience (being consumer friendly), protection and preservation (avoids leakage or break-up and protects against microbial contaminants, offering longer shelf life), marketing and communication (real-time information about the quality of enclosed food stuffs, besides the nutritional constituents and preparatory guidelines (Figure 1; Silvestre et al., 2011; Vanderroost et al., 2014).

In the twenty-first century, food producers/processors/ vendors and consumers, seeks novel and resourceful food packaging systems, with committed food safety, quality and traceability. This demand needs innovative tools/technology that can be assembled together for application in food packaging. The current interventions and developments in food packaging to be commercially feasible and effectively acceptable, must meet regulatory guidelines along with a justified outcome that outweighs the associated expenses of added novel technology (Vanderroost et al., 2014). Figure 2 reflects the growing interest in this field as can be substantiated with the growing number of publications since 2000 .

The major drawback associated with food packaging material(s) is their permeable nature. None of the packaging material offers complete resistance to the atmospheric gases, water-vapors and food and packaging material presently. Among the available options organic polymer materials viz. polypropylene, polyethylene, polyethylene terephthalate, polystyrene and polyvinyl chloride, remain the main choice material in food packaging industry, favored due to their lesser cost, simple processing and light weight. However, the key problem rests in their inherent permeability to gases and other small molecules.

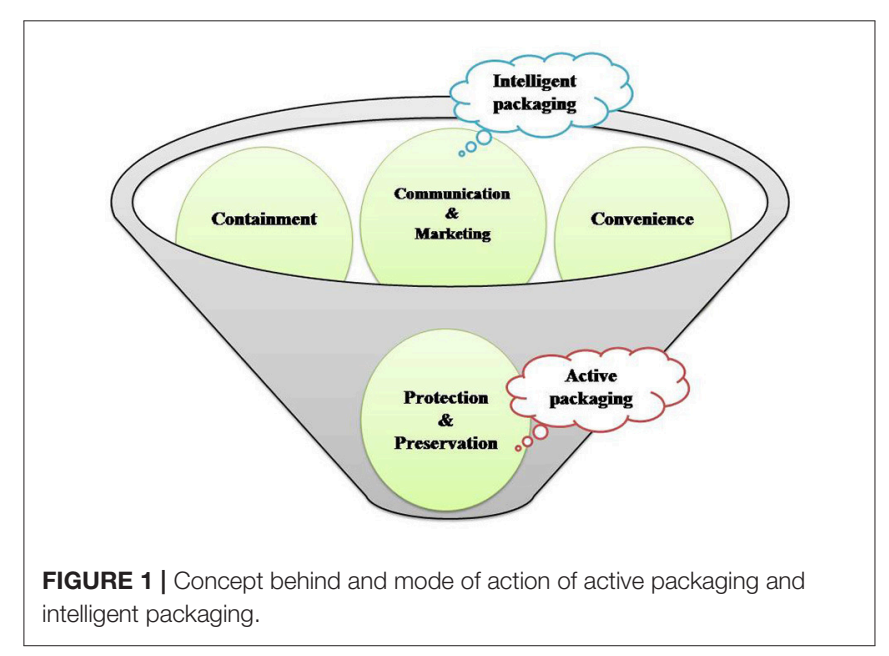




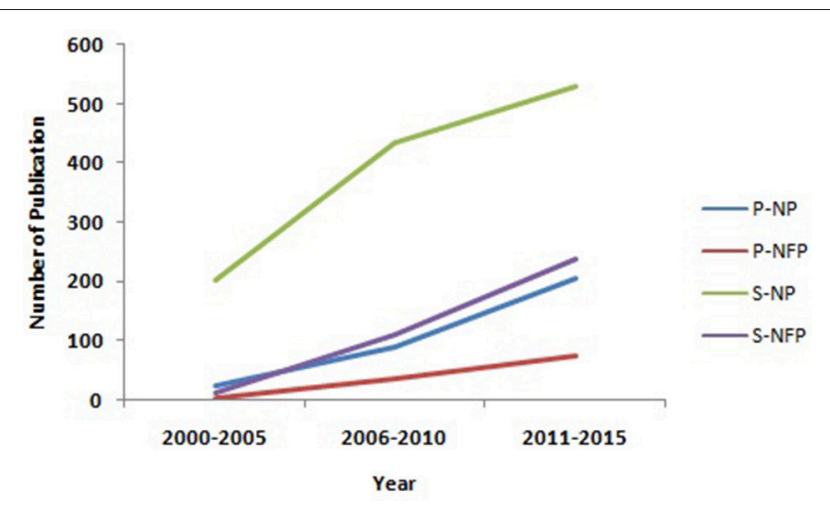

FIGURE 2 | The global trend of research interest in nano packaging (NP) and Nano food packaging (NFP), as estimated by the number of Pubmed (P) and Scopus (S) publications hits from 2000 to 2015 (Source: http://www.ncbi.nlm. nih.gov/pubmed; https://www-scopus-com.scopeesprx.elsevier.com/).

A sole polymer fails to offer all the desirable properties needed for efficient food packaging; so blending of polymer(s) or complex multilayer films is generally preferred (Robertson, 2012). This lacuna can be sorted out by using polymer nanocomposites as food packaging materials. Nanomaterials are commonly classified into nanoparticles (NPs), nanoclays (NCs) and nanoemulsions (NEs) which have numerous applications in food sector (Ranjan et al., 2014). Basically, the applications of polymer nanomaterials for food packaging will be discussed under three sections i.e., improved, intelligent/smart and active packaging. In case of improved packaging; the nanoparticles application in the polymer matrix improves the elasticity, gas barrier characteristics and stability of temperature/moisture parameters. Intelligent packaging offers superior functionality in terms of communication and marketing. It provides dynamic feedback on the actual quality of packaged food and also acts as a guard against fraudulent imitation. Active packaging assures protection and preservation based on mechanism(s) activated by intrinsic and/or extrinsic factors (Lim, 2011; Silvestre et al., 2011). Active packaging incorporates the active constituent using nanotechnology into a food package material and the carrier component can interact with internal and/or external factors, thereby stimulating actions, which increases the shelflife, food quality and safety of the food product. However, in case of intelligent packaging systems, the nanotechnology based indicator/sensor(s) are incorporated into the food package, where they can interact with internal (food components and headspace) and external environmental factors (Figures 3, 4; Mihindukulasuriya and Lim, 2014).

\section{IMPROVED PACKAGING THROUGH NANOCOMPOSITES}

Nanocomposites, a fusion of traditional food packaging material with nanoparticles are gaining active interest in food packaging sector. In addition to its remarkable antimicrobial spectrum, it displays great mechanical performance and tough resistant
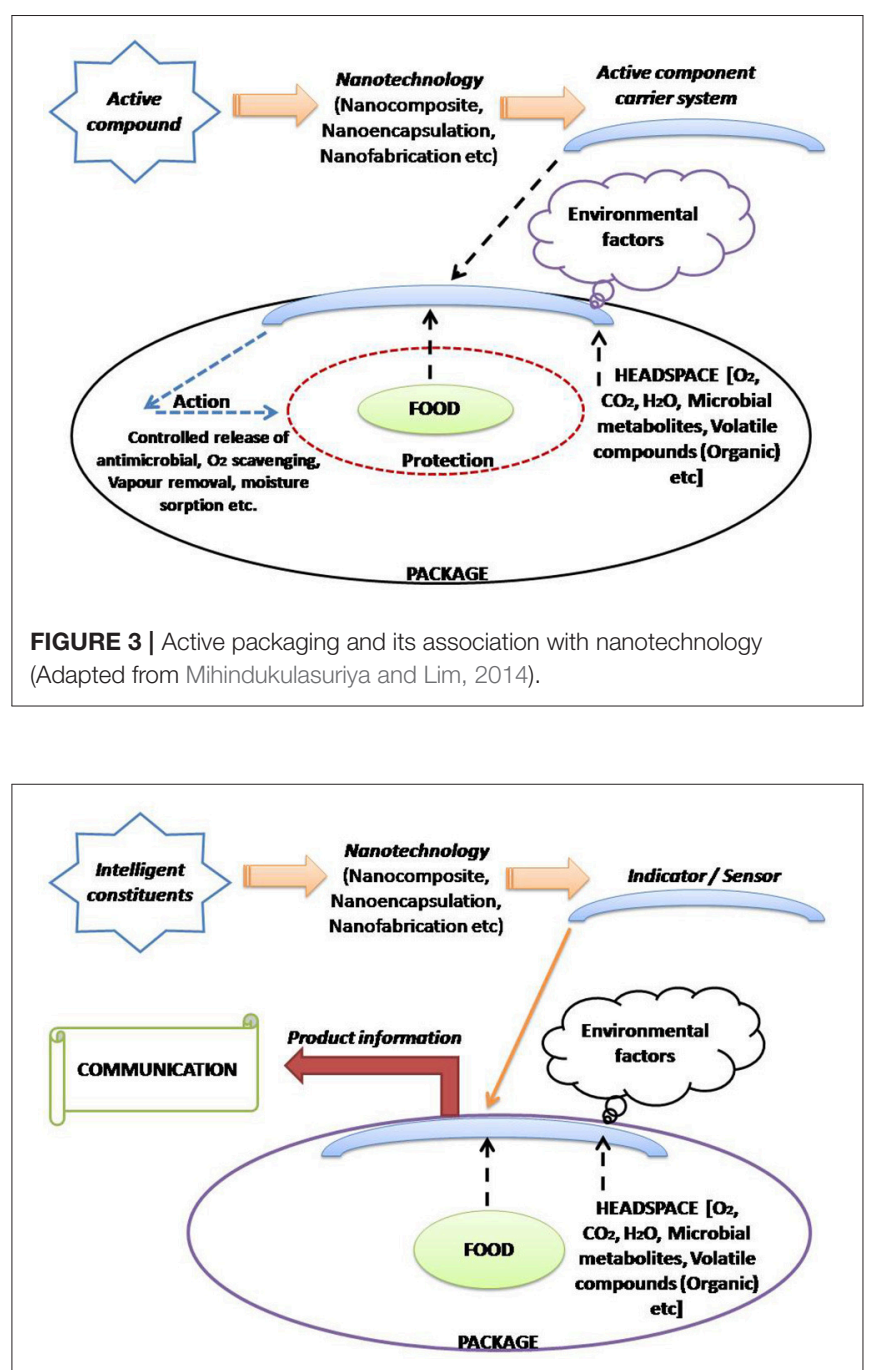

FIGURE 4 | Demonstration of intelligent packaging concept and its association with nanotechnology (Adapted from Mihindukulasuriya and Lim, 2014).

characteristics (Montazer and Harifi, 2017). Nanocomposites are usually made up of a polymer matrix in a continuous or discontinuous phase (Arora and Padua, 2010). It is a multiphase material resulting from the amalgamation of matrix (continuous phase) and a nano-dimensional material (discontinuous phase). Based on the nano-material, the nano-dimensional phase is generally characterized into nanospheres or nanoparticles, nanowhiskers or nanorods, nanotubes and nanosheets, or nanoplatelets (Bratovcic et al., 2015). Nano-sized phases augment the mechanical properties of polymer, where the elastic strain is transferred to nano-reinforced material. Owing to this property, nanocomposite has been recognized as a gold standard for improvising the mechanical and barrier characteristics of polymers (Othman, 2014). Besides improving the mechanical and barrier characteristics, nanoparticles also append active or smart properties to the packaging system (Duncan, 2011). The application of nanotechnology in polymer science can open new avenues for improving the characteristic features and 
cost-price-competence of packaging materials (de Azeredo et al., 2011; Malathi et al., 2014).

Polymer nanocomposites (PNCs), the mixtures of polymers with inorganic or organic fillers with particular geometries (fibers, flakes, spheres, particulates) have been recently introduced as novel packaging materials (Prateek et al., 2016). The aspect ratio (the ratio of largest to smallest dimension of filler) of packaging filler material plays a significant role. Fillers having higher aspect ratios possess more specific surface area, with associated high reinforcing properties (Dalmas et al., 2007; Rafieian and Simonsen, 2014). Various nanomaterials such as silica (Bracho et al., 2012), clay (Schuetz et al., 2011), organo-clay (Ham et al., 2013), graphene (Lee et al., 2013), polysaccharide nanocrystals (Lin et al., 2012), carbon nanotubes (Swain et al., 2013), chitosan (Chang et al., 2010), cellulose-based (Sandquist, 2013), and other metal nanoparticles, such as, $\mathrm{ZnO}_{2}$ (Esthappan et al., 2013), colloidal Cu (Cardenas et al., 2009), or Ti (Li R. et al., 2011) are being extensively explored as fillers.

\section{CLAY AND SILICATE NANOPLATELETS}

Clay and silicates, owing to their availability, low cost and relatively simple processibility have attracted focus of researchers as potential nanoparticles. The layered silicates, about $1 \mathrm{~nm}$ thick to a few microns long are usually employed in nanocomposites in their two-dimensional structure. The combination of silicates and polymers impart excellent barrier properties. This combination enhances the diffusive path for an infiltrate molecule (Mirzadeh and Kokabi, 2007; de Azeredo, 2009). In addition to the typical tactoid structure of microcomposites, interaction among layered silicates and polymers may result in intercalated or exfoliated nanocomposites (Figure 5). The intercalated nanocomposites represent a multilayerd structure with alternating polymer/inorganic layers lying apart by few nanometers. Such structures results through the penetration of polymers chains into the interlayer region of clay lead (Weiss et al., 2006; Pradhan et al., 2015). The exfoliated nanocomposites comprises of extensive polymer penetration with random dispersion of clay layers (Luduena et al., 2007). Application of montmorillonite clay as a nanocomponent in extensive variety of polymers such as, polyethylene, nylon, polyvinyl chloride, and starch dates back to 1990s (Montazer and Harifi, 2017). Montmorillonite (MMT) $\left[\mathrm{Mx}\left(\mathrm{Al}_{4}\right.\right.$-xMgx $\left.) \mathrm{Si}_{8} \mathrm{O}_{20}(\mathrm{OH})_{4}\right]$ is the most common clay filler. It represents an octahedral sheet of $\mathrm{Al}$ $(\mathrm{OH})_{3}$ between silica tetrahedral bi-layers (Weiss et al., 2006; Mittal, 2009), linked together by weak electrostatic forces (Tan et al., 2008). The imbalance between the surface negative charges is compensated by the presence of exchangeable cations, $\mathrm{Na}^{+}$and $\mathrm{Ca}^{2+}$ (Tan et al., 2008). The clay layers offers resistance to gases and water vapor permeability (Koh et al., 2008; Lotti et al., 2008; Adame and Beall, 2009). Further, addition of clays improves the mechanical strength of biopolymers (Ghanbarzadeh et al., 2015; Gutierrez et al., 2017). The application of 5\% (w/w) of clays in thermoplastic starch (TPS)/clay nanocomposites, improves the mechanical properties with decreased water vapor permeability of starch biopolymer (Muller et al., 2012). Clay nanoparticles

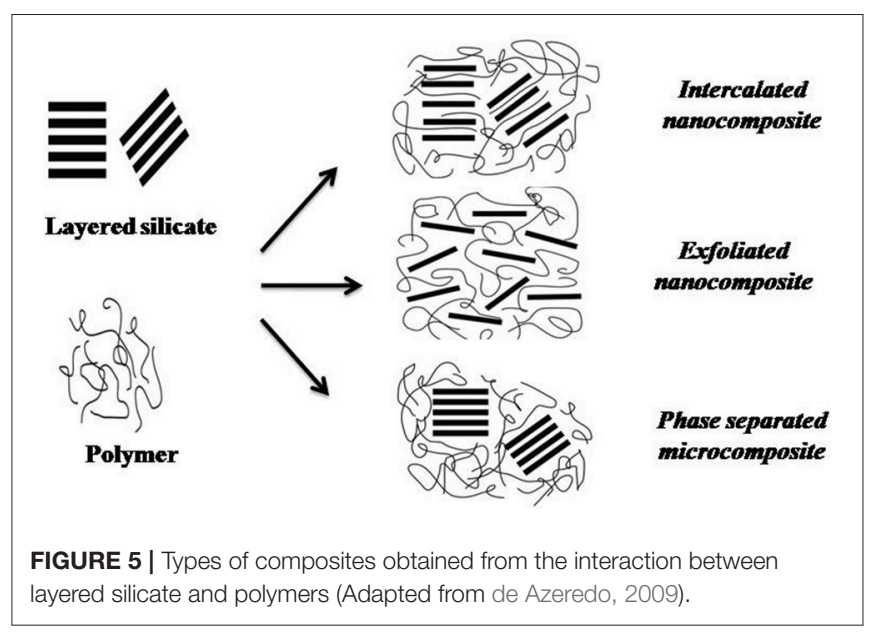

are further known to impact the glass transition (Petersson and Oksman, 2006) and thermal degradation temperatures (Cyras et al., 2008). Nano-clays also have prospects in active and intelligent food nano-packaging. Recently, Gutierrez et al. (2017) proposed a nano-packaging system developed by inserting blueberry extract between the silicate interlayer spaces of clay. Blueberries possess anthocyanins which changes color with $\mathrm{pH}$, attributed to a shift between quinoidal and flavylium forms. Incorporation of blueberry extract could modify these clays into active and intelligent nanocomposites.

\section{CELLULOSE-BASED NANOFIBERS OR NANOWHISKERS}

Cellulose, the building material of long fibrous cells, is a highly strong natural polymer. It is ubiquitous, cost-effective, environmentally friendly and easy to recycle. Cellulose is also explored as a supporting material for many nanomaterials. Application of cellulose increases the surface area of nanoparticles associated with their enhanced activity. These additive features make cellulose nanofibers an attractive class of nanomaterials (Podsiadlo et al., 2005; de Azeredo et al., 2011; Arora et al., 2016). Basically two types of nano reinforcements viz. microfibrils and whiskers, can be derived from cellulose. The cellulose chains appear as microfibrils (or nanofibers), which are bundles of molecules that are elongated and stabilized through hydrogen bonding (Wang and Sain, 2007; Kumar and Kumbhat, 2016). Each microfibril is further formed by aggregation of elementary fibrils, which contain crystalline and amorphous parts. The crystalline parts can be isolated by acid hydrolysis treatments; and are referred to as whiskers, nanocrystals, nanorods or rod like cellulose microcrystals (Lima and Borsali, 2004; Chirayil et al., 2014). The dimensions of whiskers, after hydrolysis mainly rely on the percentage of amorphous regions in the bulk fibrils, which differ between different organisms (Gardner et al., 2008). Microcrystalline cellulose (MCC) consists of huge quantity of cellulose microcrystals associated with amorphous areas (Petersson and Oksman, 2006). 
Cellulose based nano reinforcements improve the strength, thermal characteristics and modulus of polymers, with restricted elongation (Petersson and Oksman, 2006; Kumar and Kumbhat, 2016). The assimilation of cellulose nanowhiskers and starch systems improve their thermo-mechanical characteristics, along with reduced water sensitivity and intact biodegradability (Lima and Borsali, 2004). Cellulose nano reinforcements also improvised the moisture barrier properties of polymer films (Svagan et al., 2009). Earlier, Ghaderi et al. (2014) prepared an all-cellulose nanocomposite (ACNC) film consisting of sugarcane bagasse nanofiber and N,N-dimethylacetamide/lithium chloride as solvent. The study utilized a very low-value agricultural waste product for preparing a high performance nanocomposite with a tensile strength of around $140 \mathrm{MPa}$.

\section{CARBON NANOTUBES}

Carbon nanotubes (CNTs) are available as either single wall nanotube (SWNT) or multiwalled nanotubes (MWNT). SWNT is generally one atom thick, whereas, MWNT comprises of several concentric tubes with very high aspect ratios and elastic modulus (Zhou et al., 2004; Moghadam et al., 2015). The tensile strength/modulus of several polymers such as polyethylene naphtalate, polyvinyl alcohol, polyamide and polypropylene have been improvised by incorporating carbon nanotubes and polyamides (Zeng et al., 2006; Kim J. Y. et al., 2008; Prashantha et al., 2009). CNTs possess elastic modulus of upto1TPa and tensile strength of $200 \mathrm{GPa}$ (Lau and Hui, 2002). CNTs exhibit antibacterial properties, attributed to their direct penetration through microbial cells (Kang et al., 2007; Kuswandi, 2017). Dias et al. (2013) documented that CNTs in combination with allyl isothiocyanate could inhibit Salmonella choleraesuis for over a period of 40 days of storage. Asgari et al. (2014) reported that CNTs infused with polyethylene films used for the packaging of Mazafati dates, prevented fungal invasion for up to 90 days. Single-walled carbon nanotubes with cobalt mesoarylporphyrin complexes has also been explored for developing a chemiresistive detector, which detects amines generated during spoilage of meat (Liu et al., 2015). However, in spite of having wide application, concerns associated with their processing and dispersion aspects, along with high cost, limits their incorporation in nanocomposites (Arora and Padua, 2010; Moghadam et al., 2015).

\section{STARCH NANOCRYSTALS}

Starch has been extensively explored over decades as a choice material for food packaging applications. Several associated benefits viz. abundance, biocompatibility, non-toxicity, low cost, biodegradability, easy availability, and stable in air (Dandekar et al., 2012; Wesley et al., 2014) further enhances its possible applications. The incorporation of inorganic materials and synthetic polymers further improves its water resistance properties (Cyras et al., 2008). Native starch granules can be submitted to an extended-time hydrolysis at temperatures below the gelatinization temperature when the amorphous regions are hydrolyzed allowing separation of crystalline lamellae, which are more resistant to hydrolysis. The starch crystalline particles show platelet morphology with thicknesses of 6-8 $\mathrm{nm}$, improve tensile strength and modulus of pullulan films, with decreased elongation property (Kristo and Biliaderis, 2007; Arora and Padua, 2010). It has been proposed that the positive charge present over any antimicrobial agent contributes to its antimicrobial activity. As a result, the antimicrobial spectrum of metals incorporated/adsorbed on to polysaccharides surface increases, owing to enhanced surface area (Arora et al., 2016).

\section{CHITIN/CHITOSAN NANOPARTICLES}

Chitosan, a heteropolysaccharide is known for its biocompatibility, biodegradability, along with metal complexation. The polycationic nature of chitosan is mainly accountable for its wide antimicrobial activity (Arora et al., 2016). Chitosan nanoparticles are formed through ionic gelation, where the positively charged amino groups of chitosan electrostatically interacts with the polyanions engaged as cross-linkers (LopezLeon et al., 2005; Ahmed and Aljaeid, 2016; Kumar and Kumbhat, 2016). Earlier, Lu et al. (2004) observed that the combination of chitin whiskers with soyprotein isolate (SPI) thermoplastics significantly enhanced the tensile characteristics of the matrix and their resistance to water. Later, Burdock (2007) proposed hydroxypropyl methylcellulose (HPMC) act as a potential material for edible packaging films. De Moura et al. (2008) added that the chitosan based nanocomposites in HPMC helped in the improvement of the mechanical and barrier characteristics. Tripathi et al. (2009) developed a chitosan-based antimicrobial film comprising of chitosan and polyvinyl alcohol. The developed film could effectively extend the shelf-life of tomato, displaying antibacterial activity against E. coli, S. aureus, and B. subtilis. Edible films and coatings prepared from chitosan improvised physicochemical and microbiological quality of fresh-cut vegetables and fruits (Ce et al., 2012; Ramos et al., 2012). The active antibacterial bags consisting of chitosan/polyethylene have displayed efficacy in inhibiting total aerobic mesophilic bacteria, coliforms, molds, and yeasts in chicken drumsticks; besides maintaining $\mathrm{pH}$, color, and hardness of samples (Soysal et al., 2015). Chitosan/silver, chitosan/gold and chitosan/cinnamaldehyde nanocomposite films have demonstrated antimicrobial activity against E. coli, $S$. aureus, $P$. aeruginosa, Aspergillus niger, and Candida albicans (Youssef et al., 2014; Rieger et al., 2015).

\section{ACTIVE PACKAGING}

Unlike conventional food packaging, an active packaging is intentionally designed packaging system that incorporates components that would release (antimicrobial or antioxidant agents) or absorb (oxygen or water vapor) material into or from the packaged food or the food environment. Amalgamation of active compounds viz. antimicrobial agents, preservatives, $\mathrm{O}_{2}$ and water vapor absorbers, ethylene removers etc. with polymer renders it more effective for boosting the shelf life and quality of 
food product (Arora and Padua, 2010; Ranjan et al., 2014; Majid et al., 2016).

\section{INORGANIC NANOPARTICLES}

Various metals [Silver $(\mathrm{Ag})$, Gold $(\mathrm{Au}), \mathrm{Zinc}(\mathrm{Zn})]$ and metal oxide [Titanium dioxide $\left(\mathrm{TiO}_{2}\right)$, zinc oxide $(\mathrm{ZnO})$, silicon oxide $\left(\mathrm{SiO}_{2}\right)$ and magnesium oxide $\left.(\mathrm{MgO})\right]$ derived nanomaterials have been explored in diverse active packaging applications (Bikiaris and Triantafyllidis, 2013). These particles either function on direct contact or they can migrate slowly and react preferentially with organics present in the food. Nanoparticles antimicrobial activity might be due to one of these mechanisms: direct interaction with the microbial cells (interrupting transmembrane electron transfer, disrupting/penetrating the cell envelope); oxidizing cell components; and production of secondary products (e.g., reactive oxygen species - ROS or dissolved heavy metal ions), leading to cell damage (Figure 6) (Li et al., 2008).

\section{Silver Nanoparticle}

Silver nanoparticles are among the most explored nanoparticles, owing to their established antimicrobial potential against multiple commensal and pathogenic strains (Kumar and Munstedt, 2005). Besides bacterial strains, silver nanoparticles are known to be inhibitory against multiple fungi and also several viruses (HIV and monkeypox; Duncan, 2011). Silver targets bacterial metabolism by binding to its DNA, proteins and enzymes; resulting into bacteriostatic effects (Cavaliere et al., 2015). Silver nanoparticles destabilize and disrupt both the outer and cytoplasmic membranes (Morones et al., 2005). Silver nanoparticles also inhibit the respiratory chain enzymes and can also stimulate the production of reactive oxygen species (ROS) (Emamifar et al., 2011b). Earlier, Damm et al. (2008) evaluated the effectiveness of polyamide 6 and silver micro and

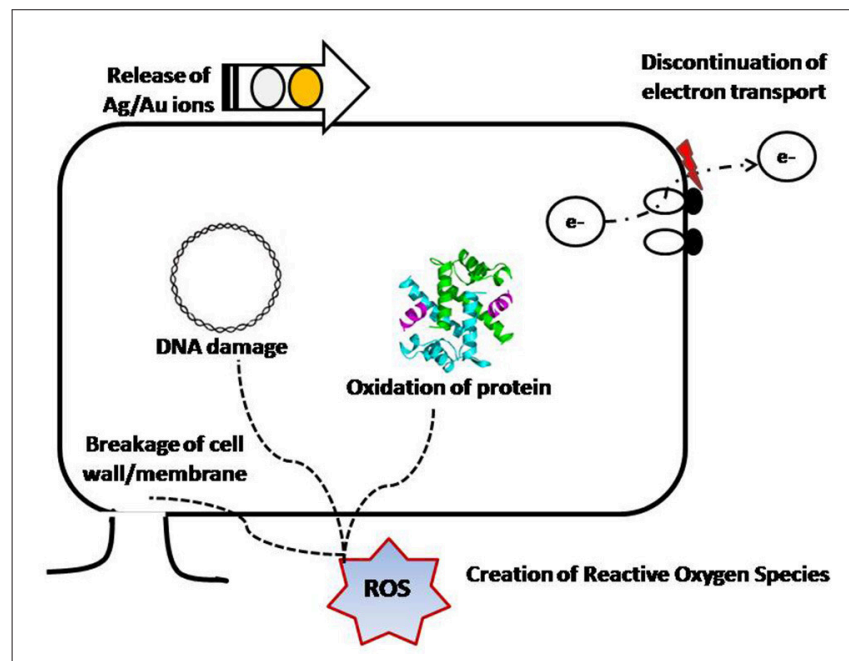

FIGURE 6 | Different mechanisms of antimicrobial activity exhibited by nanoparticles (Modified from Li et al., 2008). nanoparticles incorporated films against E. coli. The developed nano-particles based film completely inhibited the E. coli growth. However films with silver micro particles killed $80 \%$ of the bacteria. Rhim et al. (2014) reported noteworthy antimicrobial activity of silver nanoparticles incorporated agar films against Listeria monocytogenes and E. coli O157:H7. In an earlier study, Busolo et al. (2010) documented strong antibacterial activity of PLA/silver-OMMT nanocomposite against Salmonella spp. Antibacterial activity of nanocomposite systems such as PVA dispersed with cellulose nanocrystals and silver nanoparticles has been displayed against E. coli and Staphylococcus aureus (Fortunati et al., 2013a,b; Sadeghnejad et al., 2014). Lin and co workers analyzed the antimicrobial effect of cellulose/chitosansilver and cellulose/chitosan nanocomposite films and reported better activity in films with silver nanoparticles (Lin et al., 2015). Fayaz et al. (2009) studied biosynthesized silver nanoparticles incorporated into sodium alginate films in food packaging, and showed noteworthy antibacterial effect against $E$. coli and $S$. aureus. In another study conducted by Sanchez-Valdes et al. (2009), silver nanoparticles deposited over multilayered linear low density polyethylene (LLDPE) showed 70\% reduction of Aspergillus niger. Recently, Hasim et al. (2015) observed the UV/ozone treated commercial low-density polyethylene (LDPE) films coated by layer-by-layer (LbL) method by alternating the deposition of polyethyleneimine (PEI) and poly(acrylic acid) (PAA) polymer solutions and antimicrobial silver. They demonstrated that the resultant films containing antimicrobial Ag NPs could be explored in antimicrobial packaging. De Moura et al. (2012) reported that size of nanoparticles also affects the antimicrobial efficacy as they evaluated the antibacterial properties of hydroxypropyl methylcellulose films containing silver nanoparticles with diameters of 41 and $100 \mathrm{~nm}$ against E. coli and S. aureus and observed that silver nanoparticles with smaller size (i.e., $41 \mathrm{~nm}$ ) had greater antibacterial properties than the larger one.

Silver zeolites are also used to create antibacterial polymer composites. AgNP-based nanocomposites are stable and offer slow release of silver ion into stored foods, resulting in persistent antimicrobial activity. In a study where $\mathrm{AgNP} / \mathrm{SiO}_{2}$ nanocomposite material was compared with that of $\mathrm{Ag}$ zeolite and $\mathrm{AgNO}_{3} / \mathrm{SiO}_{2}$ composite, effective antimicrobial activity was displayed by both the materials; however, longer period of activity was displayed by the nancomposite; while a better immediate effect was observed with zeolite-based material. Nanocomposite based silver nanoparticles may find application in food packages requiring longer transportation or storage. To explore the antimicrobial potential of AgNP on the shelf life of food, various AgNP/polymer nanocomposite materials have been inspected within actual food systems. Fayaz et al. (2009) proposed an edible antibacterial film of alginate and AgNPs over sterilized carrots and pears. An et al. (2008) documented that coating of fresh asparagus spears with AgNP/polyvinyl pyrrolidone nanocomposite films, extended its shelf life by 25 days at refrigerated storage. When the Chinese jujube fruit was stored in bags made up of AgNP/nanoparticulate $\mathrm{TiO}$ /polyethylene films, lesser decaying rate along with delayed ripening over a period of 12 days was observed (Li et al., 2009). Orange juice stored at $4^{\circ} \mathrm{C}$ 
in LDPE films having $\mathrm{P} 105\left(\mathrm{TiO}_{2}\right.$ and $10 \mathrm{~nm}$ nanosilver mixture) displayed considerable reduction in Lactobacillus plantarum growth over the storage period of 112 days (Emamifar et al., 2011a). Recently, Orsuwan et al. (2016) prepared binary blend films comprising of agar and banana powder $(\mathrm{A} / \mathrm{B})$ composite films reinforced with silver nanoparticles (A/B/AgNPs). These films displayed strong antibacterial activity against $E$. coli and L. monocytogenes. With the increase in the concentration of banana powder, characteristics such as UV light absorption, water vapor barrier and antioxidant activity of $\mathrm{A} / \mathrm{B}$ blend also amplified whereas their mechanical properties decreased. Fernandez et al. (2010a) observed another kind of application i.e., AgNPs containing cellulose pads, which reduces the levels of microbial exudates of meat stored in modified atmosphere packaging. In a follow up study, antimicrobial activities of AgNP-containing cellulose pads were displayed in fresh foods, along with slower ripening rates with extended shelf lives (Fernandez et al., 2010b). Further, cellulose pads containing silver nanoparticles have also been successfully applied for beef coating, wherein significant reduction in microbial load was reported (Smolkova et al., 2015).

\section{Other Antimicrobial Nanoparticles}

Copper nanoparticles were shown to inhibit the growth of Saccharomyces cerevisiae, E. coli, S. aureus and L. monocytogenes on a polymer composite after $4 \mathrm{~h}$ exposure (Cioffi et al., 2005). Sheikh et al. (2011) also revealed good antibacterial effect of copper nanoparticles against E.coli and B. subtilis in polyurethane nanofibers containing copper nanoparticles. Copper nanoparticles leads to multiple toxic effects such as, generation of reactive oxygen species (ROS), lipid peroxidation, protein oxidation and DNA degradation; which might be responsible for its antimicrobial activity (Chatterjee et al., 2014). Zinc nanocrystals have also been used as an antimicrobial and antifungal agent, when incorporated with plastic matrix (Vermeiren et al., 2002). Different nanoparticles oxide(s) such as titanium dioxide $\left(\mathrm{TiO}_{2}\right)$, zinc oxide $(\mathrm{ZnO})$, silicon oxide $\left(\mathrm{SiO}_{2}\right)$, and magnesium oxide $(\mathrm{MgO})$ do found application in food packaging, due to their ability to act as UV blockers and photo-catalytic disinfecting agents (Fujishima et al., 2000). Among all, $\mathrm{TiO}_{2}$ particles have been most promising (Kong et al., 2010; Farhoodi, 2016). The antimicrobial activity of $\mathrm{TiO}_{2}$ nanoparticles is photocatalyzed and these antimicrobial particles are active only in the presence of UV light. $\mathrm{TiO}_{2}$ nanoparticles displayed good activity against $S$. choleraesuis, Vibrio parahaemolyticus, and L. monocytogenes under UV illumination but not in the dark (Robertson et al., 2005).

\section{Titanium Dioxide $\left(\mathrm{TiO}_{2}\right)$}

Naturally, titanium dioxide exists in three primary phases i.e., anatase, rutile, and brookite; having varied crystal sizes (Naicker et al., 2005). $\mathrm{TiO}_{2}$ possess photocatalytic abilities and at nanoscale $\mathrm{TiO}_{2}$ shows surface reactivity, which connects it with biological molecules (phosphorylated proteins and peptides) and DNA (Liang et al., 2006; Brown et al., 2008). The surface energy of $\mathrm{TiO}_{2}$ nanoparticles amplifies with size and is the significant factor in polymer/filler interaction (Naicker et al., 2005). The surface energies of rutile particles are higher than those of anatase particles of similar size. $\mathrm{TiO}_{2}$ is being highly explored in preparing several nanomaterials viz. nanoparticles, nanorods, nanowires, nanotubes, mesoporous and nanoporous $\mathrm{TiO}_{2}$ containing materials (Chen and Mao, 2006). The antibacterial properties of $\mathrm{TiO}_{2}$ is well known (Macwan et al., 2011; Montazer and Seifollahzadeh, 2011) however, the antibacterial capacity of nano- $-\mathrm{TiO}_{2}$ particles confined to the exposure of UV irradiation (Shi et al., 2008). Although, the exact mechanism of biocidal activity of $\mathrm{TiO}_{2}$ is unclear, it may be attributed to its initial oxidative attack over the outer/inner bacterial cell membrane, alterations of Coenzyme A-dependent enzyme activity, and DNA damage through hydroxyl radicals (Kubacka et al., 2014).

Cerrada et al. (2008) examined the photo-activated biocidal properties of $\mathrm{TiO}_{2}$ nanoparticles based $\mathrm{EVOH}$ films against nine microorganisms (B. stearothermophilus, S. aureus, E. coli, P. fluorescens, Bacillus sp., L. plantarum, E. caratovora, P. jadinii, $Z$. rouxii). The $\mathrm{TiO}_{2}$ nano-particles were uniformly dispersed ultrasonically. They reported over $5 \log$ reduction for B. stearothermophilus, Bacillus sp., L. plantarum and P. jadinii after $30 \mathrm{~min}$ of irradiation in the presence of the $\mathrm{TiO}_{2} / \mathrm{EVOH}$ materials. Chawengkijwanich and Hayata (2008) observed 3 log reduction in $E$. coli count over fresh cut lettuce treated with $\mathrm{TiO}_{2}$ nanoparticles coated oriented-polypropylene (OPP) film after $3 \mathrm{~h}$ of illumination. In contrary, uncoated films could reduce the E. coli count by only 1 log under similar conditions. In another study, $\mathrm{TiO}_{2}$ nanoparticle coated plastic films were evaluated against Penicillium expansum spoilage in apple, tomato and lemons. Results indicated that the growth of $P$. expansum was suppressed due to the photocatalytic properties of $\mathrm{TiO}_{2}$ particles upon exposure to light (Maneerat and Hayata, 2006). Combination of $\mathrm{TiO}_{2}$ nanoparticles with silver has been shown to enhance the antimicrobial properties (Li et al., 2009; Wu et al., 2010) to a significant level.

\section{Silicon Oxide $\left(\mathrm{SiO}_{2}\right)$}

Silica nanoparticles $\left(\mathrm{nSiO}_{2}\right)$ also have potential to improve the mechanical and/or barrier properties of various polymer matrices. Wu et al. (2002) examined the tensile characteristics (i.e., strength, modulus and elongation) of $\mathrm{nSiO}_{2}$ incorporated polypropylene (PP) matrix. Addition of $\mathrm{nSiO}_{2}$ into starch matrix could improve the tensile properties along with decreased water absorption by starch (Xiong et al., 2008). Vladimiriov et al. (2006) integrated $\mathrm{nSiO}_{2}$ in an isotactic polypropylene (iPP) matrix using maleic anhydride grafted polypropylene (PP-g-MA) and this $\mathrm{nSiO}_{2}$ enhanced the storage modulus of iPP and making the material stiffer with improvised $\mathrm{O}_{2}$ barrier capacity of matrix. Jia et al. (2007) generated polyvinyl alcohol and $\mathrm{SiO}_{2}$ nanocomposites through radical copolymerization of vinyl silica nanoparticles and vinyl acetate. The resultant nanocomposites exhibited enhanced thermal and mechanical properties, in comparison to pure polyvinyl alcohol. This feature may be due to strong covalent interactions between $\mathrm{nSiO}_{2}$ and the polymer matrix. In another study, Tang and Liu (2008) fabricated starch/PVOH/nSiO 2 biodegradable films and documented that the tensile and water resistance properties of films enhanced with an increase in their $\mathrm{nSiO}_{2}$ 
content. Additionally, increased intermolecular $\mathrm{H}$ bonding and formation of $\mathrm{C}-\mathrm{O}-\mathrm{Si}$ groups between $\mathrm{nSiO}_{2} /$ starch and $\mathrm{nSiO}_{2} / \mathrm{PVOH}$ were observed. Such bonding resulted in improvised miscibility and compatibility between the film components.

Food packaging applications of nano-silica has been explored as food contact surface materials (Chaudhry and Castle, 2011). Bayer Polymers, Germany made silicate nanoparticles enriched packaging film which retards the entrance of $\mathrm{O}_{2}$ and other gases and loss of moisture; preventing food spoilage. Nanocor Inc, Chicago, IL, USA, developed a clay nanoparticle based nanocomposite (Advantage Magazine, 2004). Salami-Kalajahi et al. (2012) reported that nanocomposites comprising of 5\% silica nanoparticles lead to the improvement of mechanical and physical properties. Recently, Farhoodi (2016) showed that the application of $\mathrm{SiO}_{2}$ nanoparticles as fillers in food packaging materials leaves a twisting pathway for gases. Chen et al. (2013) modified paper to form a lotus like super hydrophobic surface by coating with R812S silica nanoparticles and Polydimethylsiloxane (PDMS) silicone oil. The coated paper displayed strong water repellent characteristic.

\section{Zinc Oxide ( $\mathrm{ZnO})$}

Zinc oxide particles display good antibacterial activity, which further enhances with decrease in particle size. $\mathrm{ZnO}$ requires visible light for stimulation (Yamamoto, 2001; Jones et al., 2008). Its direct contact with microbial cell wall may result in destruction of bacterial cell integrity, liberation of antimicrobial ions i.e., $\mathrm{Zn}^{2+}$ ions, and generation of ROS (Sirelkhatim et al., 2015). Sawai (2003) observed that $\mathrm{ZnO}$ was the most effective antibacterial agent for $S$. aureus growth inhibition when compared to $\mathrm{MgO}$ and $\mathrm{CaO}$. Sevinc and Hanley (2010) explored that $\mathrm{ZnO}$ lessen the growth of bacterial biofilms (Streptococcus sobrinus) nearly $80 \%$ in dental materials. In an another study, Jin et al. (2009) observed different approaches i.e. powder, film, PVP capped and coating; for the application of nano- $\mathrm{ZnO}$ in food systems and concluded that nano- $\mathrm{ZnO}$ displayed antibacterial effects against $L$. monocytogenes and Salmonella enteritidis in liquid egg white and in culture media. Li et al. (2009) compared antimicrobial activity of $\mathrm{ZnO}$ powder and $\mathrm{ZnO}$ nanoparticles against food borne pathogens (Bacillus cereus, E. coli, S. aureus, S. enteridis) and observed that $\mathrm{ZnO}$ nanoparticles displayed better antibacterial activity than non-nano powder against all the tested bacteria. Petchwattana and Naknaen (2015) prepared PBS (polybutylene succinate)/thymol film and evaluated its antimicrobial activity against E. coli and S. aureus. Recently, Petchwattana et al. (2016) displayed significant antibacterial activity of poly butylenes succinate (PBS)/zinc oxide composite films against E. coli and S. aureus. Wiburanawong et al. (2014) analyzed the inhibitory activity of carvacrol oil against $S$. aureus and E. coli. Essential oils act can as a promising antimicrobial agent in PBS film but their unpleasant odors affected its acceptance. To overcome its odor, when $\mathrm{ZnO}$ is added to PBS, then the resultant product displayed better antibacterial activity devoid of any odor from volatiles (Li and Li, 2010; Murariu et al., 2011; Zaman et al., 2012).

\section{Oxygen Scavengers}

Access to $\mathrm{O}_{2}$ in the food package reduces the shelf-life of product owing to diverse degradation processes such as browning, rancidity, growth of aerobic microflora, lessening of vitamins, off-odors, off-flavors and undesirable color changes. Along with it, during storage, fresh fruits and vegetables produces some undesirable compounds i.e., production of ethylene vapor in climacteric fruits, which accelerates the postharvest ripening and shortening the shelf-life. In turn to circumvent these detrimental effects, the entry of $\mathrm{O}_{2}$ should be eradicated within the package or lessened to acceptable level according to the product. The content of $\mathrm{O}_{2}$ in the headspace of packaged food can be reduced through vacuum sealing or by generating inert gas atmosphere in the packaging $\left(\mathrm{N}_{2}, \mathrm{CO}_{2}\right)$ or both, and through the use of oxygen absorbent materials (Prasad and Kochhar, 2014). Various active packaging perceptions based on nanocomposite films have been explored for oxygen and ethylene scavenging or limit the path of oxygen diffusion (Mihindukulasuriya and Lim, 2014; Echegoyen, 2015; Montazer and Harifi, 2017). A varied number of polymers having nanostructured oxygen scavengers can be explored as active packaging material for sliced meat, poultry, beverages, cooked pasta, ready-to-eat snacks, fish etc. (Neethirajan and Jayas, 2011). Xiao et al. (2004) developed $\mathrm{O}_{2}$ scavenger films and incorporated $\mathrm{TiO}_{2} \mathrm{NPs}$ to different polymers and this nanocomposite material was further explored as packaging films in $\mathrm{O}_{2}$ sensitive food stuffs. Later on, Busolo and Lagaron (2012) modified the high density polyethylene (HDPE) films by integrating them with iron containing kaolinite to produce $\mathrm{O}_{2}$ scavenging packaging films. At nanoscale, $\mathrm{TiO}_{2}$ can be photoinduced by UV radiation and electrons got accumulated on the $\mathrm{TiO}_{2}$ surface. In photocatalytic reactions, the transfer of electron to oxygen in the air is the ratedetermining step and the photogenerated holes $(\mathrm{h}+$ ) have strong oxidation potential, which can react with water and other compounds. Xiao et al. (2004) revealed that the deposition of nanocrystalline $\mathrm{TiO}_{2}$ on glass and acetate films, formed a deoxygenated closed environment and the photocatalytic properties of $\mathrm{TiO}_{2}$ utilized for the removal of ethylene vapor to delay the ripening of climacteric fruits. Maneerat and Hayata (2006) developed $\mathrm{TiO}_{2}$ coated polypropylene films for the removal of ethylene vapor in packaged horticultural products. Ye et al. (2009) explored the photoelectrocatalytic degradation of ethylene using $\mathrm{TiO}_{2}$ supported on activated carbon; the membrane obtained is capable of degrading ethylene vapor when irradiated with UV radiation. This strategy can be explored for delaying the ripening of climacteric fruits by constantly removing the ethylene vapor during long-distance transportation.

\section{Enzyme Immobilization}

Enzymes possesses multifunctional role in food industry but possess few limitations i.e., sensitivity to processing atmosphere (temperature, $\mathrm{pH}$ ) and/or to enzyme inhibitors, sometimes restricts their applicability in food system but the concept of immobilization and incorporation of enzymes in packaging materials provides an alternative to the direct use of enzymes in food matrix (Ranjan et al., 2014). Immobilization 
at nanoscale increases the surface area and boosts the performance by enhancing the stability to $\mathrm{pH}$, temperature and resistance to proteases; besides helping controlled release of enzymes into food system (Rhim et al., 2013; Brandelli et al., 2017). According to Lopez-Rubio et al. (2006), immobilization is an efficient way to improve the stability of enzyme toward $\mathrm{pH}$ and temperature, resistance to proteases and other denaturing components and provides an ample environment for their repetitive use or controlled discharge in food system. Fernandez et al. (2008) observed that the enzymes (lactase or cholesterol reductase) inclusion to packaging substances might enhance the food product values and match the consumer requirement with enzyme deficiencies. Rhim and Ng (2007) explored the approach of enzyme adsorption into nanoclays incorporated to polymers. It is further supported by Gopinath and Sugunan (2007) that nanoclay has a high affinity for protein adsorption and could be utilized as a competent enzyme carrier. Ahuja et al. (2007) reported that conductive polymers may be explored as immobilizing matrices for biomolecules. However, Sharma et al. (2004) also validated the same by immobilizing the glucose oxidase onto films of poly (anilineco-fluoroaniline). Qhobosheane et al. (2001) modified $\mathrm{SiO}_{2}$ nanoparticles to immobilize glutamate dehydrogenase and lactate dehydrogenase, which displayed better enzyme activity after immobilization.

\section{INTELLIGENT/SMART PACKAGING SYSTEM}

Intelligent or smart packaging systems boost the communication aspect of a package and such type of advanced packaging recognize any characteristics of the packaged food and apply different mechanisms to register and convey information regarding the existing quality or condition of the food with regard to its safety and digestibility. Such system uses different innovative communication methods i.e., Nano-sensors, timetemperature indicators, oxygen sensors, freshness indicators etc. (Kerry et al., 2006; Bouwmeester et al., 2007; Majid et al., 2016). The inclusion of nanosensors in food packaging systems helps in detecting the spoilage associated changes, pathogens and chemical contaminants, and thus providing the exact scenario of food products freshness (Liao et al., 2005). Nanosensors are nanotechnology enabled sensors characterized by a range of variations. Generally, nanosensors can be applied as labels or coatings to add an intelligent function to food packaging in terms of ensuring the integrity of the package through the detection of leaks (for foodstuffs packed in a vacuum or inert atmosphere), indications of time-temperature variations (e.g., freeze-thawrefreeze), or microbial safety (the deterioration of foodstuffs) (Mahalik and Nambiar, 2010; Watson et al., 2011; Fuertes et al., 2016). Gas sensors are basically used for revealing the gaseous analyte in the package. Optical $\mathrm{O}_{2}$ sensors works on the principle of luminescence quenching or absorbance changes caused by direct contact with the analyte; whereas optochemical sensors are used to check the quality of products by sensing gas analytes such as, hydrogen sulfide, $\mathrm{CO}_{2}$ and volatile amines (Biji et al., 2015).
The unique chemical and electro-optical properties of nanoscale particles respond to environmental changes (e.g., temperature or humidity in storage rooms, levels of oxygen exposure), product degradation or microbial contamination (Bouwmeester et al., 2009). Therefore, such technology would apparently benefit consumers, industry stakeholders and food regulators (Duncan, 2011).

\section{$\mathrm{O}_{2}$ SENSORS}

Food packaging systems with restricted oxygen availability are preferred over those giving free oxygen accesses. In order to achieve this packaging needs to be carried out under vacuum or nitrogen gas along with incorporation of irreversible $\mathrm{O}_{2}$ sensors. In case of modified atmosphere packaging (MAP), the headspace $\mathrm{O}_{2}$ concentration is either deliberately reduced to an optimal level or entirely eliminated as per food product requirements. Lee et al. (2005) developed a UV based colorimetric $\mathrm{O}_{2}$ indictor that utilizes $\mathrm{TiO}_{2}$ nanoparticles for photosensitization of triethanolamine induced reduction of methylene blue in a polymer encapsulation medium. UV irradiation leads to bleaching of sensor, which remains colorless until exposed to $\mathrm{O}_{2}$. The pace of change in color is relative to the level of $\mathrm{O}_{2}$ exposure (Gutierrez-Tauste et al., 2007). Mills and Hazafy (2009) used nanocrystalline $\mathrm{SnO}_{2}$ as photosensitizer and a colorimetric $\mathrm{O}_{2}$ indicator consisting of glycerol (as electron donor), methylene blue (a redox dye) and hydroxyethyl cellulose (as encapsulating polymer). Upon exposure to UV-B light, indicator gets bleached and photoreduction of dye takes place by $\mathrm{SnO}_{2}$ nanoparticles. Another study done by Mihindukulasuriya and Lim (2013) generated UV based activated $\mathrm{O}_{2}$ indicator membrane through electrospinning method. Encapsulating of the active components viz. $\mathrm{TiO}_{2}$ nanoparticles, glycerol and methylene blue within electrospun poly fibers, enhanced the oxygen sensitivity of the membrane.

\section{$\mathrm{CO}_{2}$ SENSOR}

To monitor freshness or quality of packaged foods during their storage condition, Jung et al. (2012) formed chitosanbased $\mathrm{CO}_{2}$ indicator. For the enhancement of signal strength of indicator, 2-amino-2-methyl-1-propanol (AMP) was used as an additive to the chitosan solution. The indicator solution of chitosan and AMP can be easily packed into sachets, which are permeable to gaseous $\mathrm{CO}_{2}$ inside food packages. Borchert et al. (2013) develop an optochemical $\mathrm{CO}_{2}$ sensor which uses a phosphorescent reporter dye phosphorescent Pt-porphyrin PtTFPP and a colourimetric $\mathrm{pH}$ indicator (naphtholphthalein) integrated in plastic matrix together with a phase transfer agent (tetraoctyl or cetyltrimethyl ammonium hydroxide). The sensor material was optimized for food packaging applications and underwent complete characterization with respect to its $\mathrm{CO}_{2}$ sensitivity and cross-sensitivity to $\mathrm{O}_{2}$. Puligundla et al. (2012) concluded that the optical $\mathrm{CO}_{2}$ gas sensors, particularly, dry optical sensors having $\mathrm{pH}$-sensitive dye indicators can be explored for food packaging applications. 


\section{DETECTION OF SPOILAGE AND PATHOGENIC MICROORGANISMS}

According to CDC (2011), approximately 48 million cases of food-borne illnesses are reported per year in USA. It was estimated that reduction in incidence of food borne infection by even $1 \%$ would benefit about 500,000 individuals (Scallan et al., 2011). Food borne illness caused by bacteria, fungi or viruses remains a matter of public health concern. The need of hour is to develop a detection method which is rapid, precise, and cost effective (Duncan, 2011). Currently followed detection methods mainly explore immunological assays dependent over the selective interaction between antibody and antigen. Microbial sensors exploring nanoparticles do also work on similar approach besides having unique optical and electrical characteristics in conjunction with other properties such as spacious and simply functionalized surfaces.

Antibodies conjugated to nanomaterials such as quantum dots (QD) are mainly explored for detection of bacteria. QDs are mainly employed due to their characteristic high fluorescence efficiency, stability for photobleaching, high sensitivity, extended decay life-time and electronic properties such as, wide and continuous absorption spectra and narrow emission spectra (Valizadeh et al., 2012). Yang and Li (2006) explored QDs for detection of E. coli O157:H7 and Salmonella Typhimurium. Highly fluorescent CdSe/ZnS QDs were conjugated to anti E. coli $\mathrm{O} 157$ and anti-Salmonella antibodies. QDs for E. coli and Salmonella had different emission wavelength but shared common excitation wavelength, allowing simultaneous detection of the two test pathogens. The QD conjugate method has several benefits over typical fluorescence dyes. QDs possess significantly higher fluorescence intensity, offer resistance to photobleaching and have additional advantage of multiplexed detection using different QDs (Mihindukulasuriya and Lim, 2014).

QDs and organic fluorescent compounds (OFC) are classified into down-conversion phosphors and up-conversion fluorescent nanoparticles (UCNPs). The down-conversion phosphorus absorbs energy at low wavelength and emits radiation at higher wavelength whereas; UCNPs get excited by low energy radiations (near-infrared) and emit higher energy visible radiation. These characteristic features help them to rule out autofluorescence and photodamage related problems. UCNPs are extremely sensitive sensors that can also be used for bacteria, enzyme, protein, nucleic acid, $\mathrm{pH}, \mathrm{NH}_{3}, \mathrm{CO}_{2}$, and other analytes (Gnach and Bednarkiewicz, 2012). Ong et al. (2014) conjugated E. coli specific antibodies to citrate modified oleic acid-capped NaYF4:Yb, Er UCNPs for selective detection of E. coli. Earlier, up-conversion conjugates technique was used to design a quick lateral flow test, for E. coli detection (Niedbala et al., 2001). It is also applied for multiplex detection of other drug compounds. QDs and UCNPs have found application in imaging, labeling and medicine. Further, they can have potential application in food packaging; particularly for awaited advancement in intelligent label for pathogen and toxins detection in food matrix. Therefore, more R\&D needs to be done to further establish this technique in food packaging application.

\section{FRESHNESS INDICATORS}

Freshness indicators aim to provide the actual information regarding the quality of food product during storage, transit and display. The reaction between microbial metabolites and incorporated indicators gives visual information about the microbial quality of product (Biji et al., 2015). The incorporated freshness indicators are sensitive to spoilage compounds or microbial metabolites generated during spoilage of food product, for example volatile sulfides and amines (Mihindukulasuriya and Lim, 2014; Fuertes et al., 2016). The approach for the recognition of pathogens in food system depends upon the isolation of pathogens from the food environment (Rossi et al., 2017). Smolander et al. (2004) detects the spoilage of meat products by depositing a transition metal (silver or copper) coating (1-10 $\mathrm{nm}$ thick) over plastic film or paper packaging structures. This coating turns dark upon reacting with sulfide volatiles produced from fresh meats undergoing spoilage. Maynor et al. (2007) develop a conjugated poly (thiophene) to produce multi-dimensional colorimetric effects that distinguish 22 structurally related amines with high (97\%) accuracy. The conjugated system was applied in detection of amine profiles in tuna fish. Later, a polyaniline film sensitive to a group of basic volatile amines released during spoilage of fish was developed. Such interventions are useful in real-time detection of fish spoilage at different temperatures (Kuswandi et al., 2012). Lim et al. (2013) developed a peptide receptor based portable bioelectronic nose for analyzing food freshness by targeting trimethylamine, the key volatiles produced during raw seafood spoilage. Esser et al. (2012) developed a sensor using carbon nanotubes to detect $\mathrm{CO}_{2}$, volatile compounds and ethylene emitted during the ripening of fruits.

\section{TIME-TEMPERATURE INDICATORS (TTIS)}

Chiefly, the temperature exploitations meet by food during transit and distribution are one of the main environmental factors responsible for the reduced shelf-life of foods. To counter different temperature abuses, TTIs are useful to monitor the thermal history during food storage, handling, and distribution. TTIs allow the retailers to ensure that the foods have been stored at the suitable temperatures; help consumers in determining the quality of food product they are purchasing; and help manufacturers in monitoring of supplied foodstuff throughout the supply chain (Mihindukulasuriya and Lim, 2014; Ranjan et al., 2014).

Singh (2000) grouped TTIs into three basic types viz. abuse indicators, partial temperature history indicators and full temperature history indicators. Abuse indicators designate attainment of a particular temperature. Partial temperature history indicators present the time-temperature history only if the temperature surpasses a critical set limit. In contrary, the full temperature history indicators provide a constant monitoring of temperature changes with time. The communication regarding the change in food quality is generally linked with color development associated with a temperature dependent migration 
of dye through a porous material; or change in color of an indicator. Timestrip, an AuNP based iStrip for chilled foods appear red at temperatures beyond freezing. However, accidental freezing leads to irreparable agglomeration of the AuNP, resulting in loss of the red color (Robinson and Morrison, 2010). Zeng et al. (2010) developed triangular Ag nanoplates as colorimetric indicators for monitoring the timetemperature history, based on thermodynamic un-steadiness of Ag nanoplates. The key problem regarding the application of TTIs in food is related to the kinetics of TTIs response, it should match with those of the key degradation reactions in food. In TTI systems, its synchronization and degradation kinetics is a matter of concern as their reaction cannot be programmed readily. In concern to above problem, Zhang et al. (2013) formed a TTI working on a reaction of epitaxial overgrowth of $\mathrm{Ag}$ shell on $\mathrm{Au}$ nanorods dipped in cetyltrimethylammonium chloride (CTAC) solution appears red in color because of two absorbance bands arise from transverse and plasmon resonances, respectively. With the introduction of $\mathrm{AgNO}_{3}$ and a reducing agent (ascorbic acid), Ag atoms get deposited on $\mathrm{Ag}$ nanorods and form the shell of $\mathrm{Au} / \mathrm{Ag}$ nanorods. The extinction bands of longitudinal plasmon resonance transfer to lesser wavelengths as the Ag shell thickens which leads to changes in color from red, yellow and lastly green. Kinetics of this color variation can be managed by altering the Au nanorods, CTAC, reducing agent and $\mathrm{pH}$ value. Those products which exhibited diverse degradation kinetics can be managed by such type of low cost programmable indicator.

\section{HUMIDITY INDICATORS}

Monitoring of humidity will provide an edge to know about the integrity of the package and actual status regarding the quality and safety of the food items in the package. To overcome this issue, Zhou (2013) developed humidity indicator using iridescent technology, where nanocrystalline cellulose film was made by casting to form a thick iridescent film and color of these films was adjusted so that they can interact with the electromagnetic field and such films can be explored as a humidity indicator (HI). The dry film appears to be blue-green in color whereas their color shifted to red orange exposing to high humidity. Hong et al. (2010) reported that photonic crystals displayed resistance toward photobleaching and degradation, which makes them a perfect encoding constituent. Binding of target analytes in photonic crystals leads to change in their structural period and eventually shift in their reflection wavelength. Earlier, Tian et al. (2009) using photonic crystal hydrogel concept designed a humidity color indicator through amalgamating the photonic monodispersed latex spheres of poly (styrene-methyl methacrylate-acrylic acid) with photo-polymerized acrylamide. This indicator works reversibly to the presence of relative humidity $(\mathrm{RH})$ i.e., it changes its color from transparent to violet, blue, cyan, green and red as $\mathrm{RH}$ changed from 20 to $100 \%$. Zulian et al. (2012) using the similar approach developed an emulsion radical (which is a co-polymerization of styrene and methacrylic acid monomers) and created core-shell latex particles with diverse degrees of order with an array of structural colors.

\section{CURRENT SCENARIO OF NANOTECHNOLOGY APPLICATION IN FOOD PACKAGING}

The application of nanoparticles is explored in numerous sectors such as electronics, medicine, textiles, defense, food, agriculture, and cosmetics. Nanotechnology caters several areas of food sciences such as food safety, packaging, processing, bioavailability, fortification, encapsulation, pathogen detection etc. (Weiss et al., 2006; Ravichandran, 2010). Nanotechnology based food packaging offer numerous advantages over conventional food packaging materials via improving several properties such as temperature resistance, enhanced durability, flame resistance, barrier, recycling and optical properties, processability due to lower viscosity; proficiently delivery of active materials into the biological systems, at minimum costs with lessen environmental issue. Such progressions make it an ideal candidature for the development of nano materials in wide array of food packaging applications such as processed meat and meat products, cheese, confectionery, cereals, boil-in-the-bag foods, in addition to this it also helps in extrusion-coating applications for fruit juices and dairy products, or co-extrusion processes for the manufacture of bottles for beer and carbonated drinks (Bumbudsanpharoke and Ko, 2015; Trujillo et al., 2016). The application of nanomaterials as food packaging materials has been observed by various authors in several food systems which have been summarized in Table $\mathbf{1}$.

Nanotechnology in recent years has developed into a wideranging, multibillion-dollar global industry. It can be predicted that more nanofood products will come out in the markets within the next few years. Many companies are currently applying nanotechnologies to food could be as high as 400. A number of major food and beverage companies like Altria, Nestle, Kraft, Heinz and Unilever are reported to have curiosity in nanotechnology. Numerous companies are already engaged in production of packaging materials based on nanotechnology that are extending the shelf life of food and drinks and also improving the food safety (Chaudhry et al., 2008; Chaudhry and Castle, 2011; Trujillo et al., 2016).

Nanocor ${ }^{\mathrm{TM}}$, a subsidiary of Illinois-based AMCOL International, offers ample range of polymer nanocomposites for purchase in pellet form and packaging products developed with the montmorillonite minerals such as Durethan ${ }^{\circledR}$ KU2-2601 (blending of nylon 6 and nanoclay) has been used as food packaging material via improving several properties (gas and moisture barrier, strength, toughness, abrasion, and chemical resistance) of packaging (Duncan, 2011; Cushen et al., 2012; Duran and Marcato, 2013; Bumbudsanpharoke and Ko, 2015). Honeywell International has also developed a mixture of nylon 6-nanoclay composite marketed as Aegis ${ }^{\mathrm{TM}}$ OXCE with additional $\mathrm{O}_{2}$ scavenger property. It is ideal for packaging of beer and flavored alcoholic beverage and at commercial level; it is 
TABLE 1 | Application of nanomaterials as food packaging materials in several food systems (2005-2015).

\begin{tabular}{l} 
Nanomaterial \\
\hline Oxygen indicator \\
Xanthine and hypoxanthine \\
chemical indicator \\
$\mathrm{TiO}_{2}$-coated \\
oriented-polypropylene \\
Carbon nanotubes \\
Absorbent pads containing Ag \\
nanoparticles (NPs) \\
Xanthine amperometric sensor \\
Ag montmorillonite NPs
\end{tabular}

Polyvinyl chloride (PVC) with $\mathrm{ZnO} N \mathrm{NS}$

Low density polyethylene(LDPE) films loaded with $\mathrm{Ag}$ and $\mathrm{ZnO}$ NPs Cellulose Ag nanoparticles (AgNPs)

Carbon nanotubes with allyl isothiocyanate and cellulose

Low density polyethylene with AgNPs

Ethylene vinyl alcohol (EVOH) with AgNPs

Low density polyethylene with
$\mathrm{Ag}$ and $\mathrm{ZnO}$
Pullulan with AgNPs
Polyethylene with $\mathrm{Ag}, \mathrm{TiO}_{2}$

Nanoclays with matrix of polyamide 6

Sodium alginate with $\mathrm{CaCl}_{2}$ and AgNPs

Isotactic polypropylene (iPP) with $\mathrm{CaCO}_{3}$ nanofiller

\section{$\mathrm{Ag} / \mathrm{TiO}_{2}$ nanocomposite}

Polyethylene with $\mathrm{Ag}$ and $\mathrm{TiO}_{2}$ NPs

Polyethylene with $\mathrm{Ag}, \mathrm{TiO}_{2}$

(1)

$\begin{array}{ll}\begin{array}{l}\text { Application of } \\ \text { nanomaterial }\end{array} & \text { Types of food } \\ \begin{array}{ll}\text { Nanosensors } \\ \text { Nanosensors }\end{array} & \begin{array}{l}\text { Uncooked bacon } \\ \text { Canned tuna }\end{array} \\ \text { Antimicrobial } & \text { Lettuce } \\ \text { Nanosensors } & \text { Meat } \\ \text { Antimicrobial } & \text { Poultry meat } \\ \text { Nanosensor } & \text { Fish } \\ \text { Antimicrobial } & \text { Fresh fruit salad }\end{array}$

Fresh cut carrots

Fior di latte cheese

Antimicrobial Sliced apples

Antimicrobial Orange juice

Antimicrobial

Kiwi and melon juices

Poultry and beef samples

Antimicrobial

Antimicrobial

Shredded cooked chicken

Barberry
Antimicrobial

Antimicrobial

Antimicrobial

Antimicrobial

Improved barrier properties

Antimicrobial

Antimicrobial

Antimicrobial

Antimicrobial

Chicken, pork, cheese, lettuce, apples, peels, eggshells

\section{Meat}

Tsurkey deli meat

Fresh apples, white slice bread, fresh carrots, soft cheese, atmosphere packaging milk powder, fresh orange juice Beef

\section{Fior di Latte cheese}

Apple slice

Bread

Fresh apples, white sliced bread, fresh carrots, pre-packed soft cheese, MAP milk powder and orange juice

Antimicrobial
Effect

References

Change in sensor color indicate exposure to $\mathrm{O}_{2}$

Checked the freshness of food sample

Mills, 2005

Cubukcu et al., 2007

$2 \log$ reduction of $E$. coli

Detection of pathogens in food

Effective against $E$. coli and S. aureus

Detected the freshness of sample

Inhibited the growth of spoilage

microorganisms and preserve the sensory

quality

Inhibited the growth of spoilage

microorganisms and enhanced the shelf life of

carrot by more than 2 months stored under 4

$\pm 1^{\circ} \mathrm{C}$

Extended the shelf life up to 3-5 days

Fruit decay rate was significantly lowered

Increased the shelf life of orange juice up to 28

days and inactivate Lactobacillus plantarun

99.9\% reduction of total viable count of bacteria and yeast

$90 \%$ reduction of total viable count of lactic acid bacteria

Inhibited the growth of Salmonella

2.3 log reduction in molds and $2.84 \mathrm{log}$ reductions of total bacteria

2 log reduction of bacterial (Salmonella spp., $L$. monocytogenes) count in low protein food and 1 log reduction in bacterial count in high protein food

Inhibited the growth of E. coli, P. aeruginosa and $L$. monocytogenes

Inhibited L. monocytogenes, S.aureus over 2 weeks of refrigerated storage

Inhibited the growth of Penicillium and Lactobacillus spp.

Enhanced $\mathrm{O}_{2}$ barrier properties, capability to block UV and improved stiffness of packaging Increased the shelf life upto 10 days and inhibit the proliferation of Pseudomonas spp

Increased the shelf life up to 10 days

Enhanced the shelf life of bread

Fruit decay rate was significantly lower than in the control sample upto 10 days

Inhibited the growth of Penicillium and Lactobacillus spp.
Chawengkijwanich and Hayata, 2008

Yang et al., 2008

Fernandez et al., 2009

Shan et al., 2009

Costa et al., 2011

Costa et al., 2012

Gammariello et al., 2011

Li X. et al., 2011

Emamifar et al., 2011b

Lloret et al., 2012

Dias et al., 2013

Motlagh et al., 2012

Martinez-Abad et al., 2012

Panea et al., 2013

Khalaf et al., 2013

Metak and Ajaal, 2013

Picouet et al., 2014

Mastromatteo et al., 2015

Cozmuta et al., 2015

Metak, 2015

Metak and Ajaal, 2013
Volpe et al., 2015
Fresh apples, white slice bread, fresh carrots, soft cheese, atmosphere packaging milk powder, fresh orange juice 
flourishing in South Korea (Cooper, 2013; Bumbudsanpharoke and Ko, 2015). In collaboration with Nanocor; Mitsubishi Gas Chemical Company Inc. USA developed nylon nanocomposites with commercial name Imperm ${ }^{\circledR}$ that applied in a barrier layer for multi-layer PET bottle, which is further explored for liquors (beer) andsmall carbonated soft-drink beverages. NanoTuff $^{\mathrm{TM}}$ (nylon 6 based nanocomposite with $10 \%$ clay) is commercialized by Nylon Corporation of America, which exhibit an improved barrier properties to $\mathrm{H}_{2} \mathrm{O}, \mathrm{O}_{2}$, and $\mathrm{CO}_{2}$, as comparison to neat Nylon 6 (Nanocor, 2008; Duncan, 2011).

Nonosilvers are also engaged in packaging of different food items (fruits, vegetables, herbs, breads, cheeses, soups, sauces, meats etc.) due to their varied antimicrobial properties and globally it is marketed with different commercial names like Fresher Longer ${ }^{\mathrm{TM}}$, Bags Fresher Longer ${ }^{\mathrm{TM}}$ (USA), e.Window ${ }^{\circledR}$ Nano Silver food Container (South Korea); Everin Food Containers Nano Silver Airtight, Incense Nano Silver Food Container, Fresh Box NanoSilver Food Container (South Korea), Zeomic (Japan); Anson Nano, Nano Silver Food (China) (Bumbudsanpharoke and Ko, 2015). This trend is also reflected in the emergence of escalating numeral of national and European R \& D projects allied to intelligent packaging (Vanderroost et al., 2014).

\section{POTENTIAL RISKS, HEALTH SAFETY FEATURE AND TOXICITY OF NANOPARTICLES IN PACKAGING}

Current century has observed the speedy development of nanotechnology and its impact in every field therefore for the sake of consumer(s), it is mandatory to have comprehensive information regarding the interface between nanoparticles (NP) and cells, tissues and organisms, particularly in relation to possible hazards to human health. In food science, nanotechnology has an immense impact on food packaging (Chaudhry and Castle, 2011). Nanoparticles may enter into the body through inhalation, ingestion or cutaneous exposure (Maisanaba et al., 2015). Once they penetrate into the biological environment, NP will inevitably come into contact with a huge variety of biomolecules (proteins, sugars, and lipids) which are dissolved in body fluids such as the interstitial fluid between cells, lymph or blood (Farhoodi, 2016). Studies on titania and silver nanoparticles revealed that these materials may enter blood circulation and their insolubility leads to accumulation in organs (Carrero-Sánchez et al., 2006; Kim Y. S. et al., 2008; Rhim et al., 2013). Liver and spleen are mainly responsible for distribution of nanoparticles, mediating their passage from intestine to the blood circulation (Dimitrijevica et al., 2015). A very few studies have taken note of possible toxicity of $\mathrm{NP}(\mathrm{s})$ amalgamated in food packaging, besides the data regarding their bioavailability, biodistribution and route followed is scanty. Nanoparticles may unintentionally come in GIT contact via leaching/migration of NPs from nanopackaging to food commodities ( $\mathrm{He}$ and Hwang, 2016). Migration leads to transfer of low molecular mass constituents of packaging material to packaged product. This un-intended transfer of undesirable packaging constituents may raise the safety concerns of consumers. The migration of nanoparticle(s) to food matrix mainly relies on the chemical and physical properties of food and polymer involved. Other controlling parameters includes the concentration, particle size, molecular weight, solubility and diffusivity of specific substance in polymer, $\mathrm{pH}$ value, temperature, polymer structure, polymer viscosity, mechanical stress, contact time and composition of food. The solubility of metallic NP in aqueous solution is directly proportional to temperature and inversely proportional to the $\mathrm{pH}$ which ultimately augments the migration of metal into the food matrix (Huang et al., 2015). Besides the route of entrance into the body, concentration and duration of exposure, toxicity of nanoparticles also depends upon the host susceptibility and state of organism (Sharma et al., 2009). Aschberger et al. (2011) studied the oral route of transmission and observed that signs of toxicity with relatively high doses of nano-silver or nano- $\mathrm{TiO}_{2}$ appeared. Few reports points out toward the genotoxicity and carcinogenicity of NPs. ZnO NP(s) displayed genotoxicity in human epidermal cells, even if the bulk $\mathrm{ZnO}$ is non-toxic, implying the role of particle diameter (Sharma et al., 2009). Earlier, Chithrani et al. (2006) reported that the smaller $\mathrm{NP}(\mathrm{s})$ exhibit more toxicity than larger ones. High surface area comparative to total mass of smaller NPs enhance their prospects of interaction with the biological molecules, leading to adverse responses. Other factors, such as surface functionalization also plays vital roles (Varela et al., 2012; Shang et al., 2014). Out of few reports, inhalation of very high doses $\left(10 \mathrm{mg} / \mathrm{m}^{3}\right)$ of nano- $\mathrm{TiO}_{2}$ has been associated with incidence of lung tumors. Inhalation and skin exposure routes are much more explored as compare to ingestion as a route for the entry of $\mathrm{NP}(\mathrm{s})$. Inhaled $\mathrm{MgO} \mathrm{NP}(\mathrm{s})$ can make their way to the olfactory bundle under the forebrain via the axons of olfactory nerve in the nose and can also travel to other parts of the brain through systemic inhalation. There are reports documenting the penetration of latex nanoparticles, smaller than $1 \mu \mathrm{m}$, through the outer layers of a skin, during constant flexing. In contrast, few other studies question the healthy skin penetration potential of nanostructured particles. Furthermore, inhalation of nanomaterials and probability of their entrance through skin penetration is a matter of high concern, especially for workers and consumers in direct and regular contact (Youssef, 2013). Available data shows that the circulation time increases considerably, in case the $\mathrm{NP}(\mathrm{s})$ are hydrophilic and positively charged. Love et al. (2012) also observed that cationic NP seems to be quite toxic than neutral or anionic ones, it might be due to their high affinity toward the negatively charged plasma membrane. Nel et al. (2009) also reported that a cationic NP leads to lysosomal damage and induced cytotoxicity. Nanoparticles that finds their way to bloodstream may influence the blood vessel lining and their function, may lead to blood clotting, or may even contributes toward cardiovascular diseases. Hence, it becomes imperative to obtain data about influence/impact of $\mathrm{NP}(\mathrm{s})$ over blood vessels and chances of their crossing the blood brain barrier and migration to the fetus (Dimitrijevica et al., 2015). Avella et al. (2005) showed that tiny amount of particle migration from nanocomposites to foods have been seen during packaging of food and this migration was within the limits prescribed by the European Commission (EC) for silica nanoparticles in clay nanocomposites. Likewise, studies on $\mathrm{Ag}$ and $\mathrm{ZnO}$ by Panea et al. (2013) also showed that particle migration is within limits as 
set by EC. Recently, McCracken et al. (2016) also proposed that the size, shape, material, surface charge, solubility and surface chemistry of $\mathrm{NP}_{S}$ are important in determining their toxicity. Overall data available concludes that more research is warranted before NPs may be tagged as toxic or safe. Forthcoming section briefly discusses the toxicity of some common $\mathrm{NP}(\mathrm{s})$ viz. $\mathrm{SiO}_{2}$, $\mathrm{TiO}_{2}, \mathrm{ZnO}$, and Ag.

\section{Silicon Oxide Nanoparticles}

Silica NPs may be toxic through oxidative stress generation, leading to DNA damage and induction of apoptosis. Different scientific reports support this hypothesis in intestinal epithelial cell line models. According to Tarantini and co-workers, silica NPs induced oxidative stress is probably responsible for induction of apoptosis and DNA damage. They exposed Caco-2 cells to silica NP $(15 \mathrm{~nm})$ and observed decreased cell viability and increased ROS production at $32 \mu \mathrm{g} / \mathrm{ml}$ dosage with overexpression of caspase-3 at $64 \mu \mathrm{g} / \mathrm{ml}$. Silica NPs were genotoxic to cells and augmented the frequency of micronucleus formation (Tarantini et al., 2015). As reported by Yang et al. (2014), 10$50 \mathrm{~nm}$ silica NPs induced LDH release, indicating reduced cell viability; partial inhibition of cell proliferation and a slight $S$ phase cell cycle arrest in human gastric epithelial cells (GES1) cells, and $S$ and $G 2 / M$ phase arrest in Caco-2 cells with minor increase in ROS generation. Overall they didn't report any apoptosis or necrosis, indicated that the ROS generation may accompany decreased viability and cell cycle arrest.

In contrast to the above reports, Moos et al. (2011) reported zero toxicity of silica NPs in intestinal epithelial cells. Caco-2 and colon carcinoma RKO cells showed minimal toxicity induction by silica NPs up to the dosage of $100 \mu \mathrm{g} / \mathrm{cm}^{2}$. Cells exposed to $50 \mu \mathrm{g} / \mathrm{cm}^{2}$ silica NP for $4 \mathrm{hr}$ also showed minimal changes in gene expression as determined by whole genome microarray analysis. These results are further supported by Schubbe et al. (2012), who also observed no cellular toxicity in undifferentiated Caco-2 cells when co-cultured with 32 and $83 \mathrm{~nm}$ fluorescent silica NP(s). No cytotoxicity or genotoxicity was observed in cells treated up to $200 \mu \mathrm{g} / \mathrm{ml}$ of NPs. It has also been found that the $\mathrm{SiO}_{2}$ NPs can also induce allergen-specific Th2-type allergic immune responses, as observed in an in vivo study involving female $\mathrm{BALB} / \mathrm{c}$ mice exposed to NPs. Intranasal exposure to ovalbumin (OVA) and $\mathrm{SiO}_{2}$ NPs induces a relatively high level of OVA-specific immunoglobulin IgE, IgG, and IgG1 antibodies (Yoshida et al., 2011). From the above reports, it can be concluded that the harmful effects of silica NPs are associated with high dosage (i.e., $200 \mu \mathrm{g} / \mathrm{ml}$ ) however; the same at a dose of $100 \mu \mathrm{g} / \mathrm{ml}$ are reported safe.

\section{Titanium Dioxide Nanoparticles}

$\mathrm{TiO}_{2}$ NPs have been associated with cytotoxicity mediated through oxidative stress-dependent pathways leading to DNA damage, cell cycle arrest or delay and mitochondrial dysfunction, particularly in pulmonary and inhalation models (Shi et al., 2013). However, experimental data observed in intestinal epithelial cells are in agreement that $\mathrm{TiO}_{2} \mathrm{NPs}$ are nontoxic. Koeneman et al. (2010) observed that the treatment of Caco-2 cells with $\mathrm{TiO}_{2}$ NPs $(<40 \mathrm{~nm})$ displayed a decrease in epithelial monolayer integrity by decreased TEER measurements and a loss of localization of $\gamma$-catenin to cell adherens junctions, beginning at 6 days after continuous $\mathrm{TiO}_{2} \mathrm{NP}$ treatment and long-lasting to 10 days at dose of $1,000 \mu \mathrm{g} / \mathrm{ml}$. No decrease in TEER was examined after acute exposure and no induction of cell death was reported after acute or chronic exposure. Chalew and Schwab (2013) observed the toxicity of P25 $\mathrm{TiO}_{2}(25 \%$ rutile and $75 \%$ anatase $)$ treatment $(100 \mu \mathrm{g} / \mathrm{ml})$ on the intestinal epithelial cell lines, Caco-2 and SW480. No toxicity in Caco-2 cells was observed. Few studies had supported that $\mathrm{TiO}_{2} \mathrm{NP}$ can disrupt normal microvilli structure in intestinal epithelial cells, which affects the normal cellular functions, particularly nutrient absorption (McCracken et al., 2016).

\section{Zinc Oxide Nanoparticles}

As reported earlier, $\mathrm{ZnO}$ NPs may lead to toxicity due to of the NP dissolution either in outside or within the cells, leading to enhanced availability of zinc ions, which interacts with enzymes and other cell components; oxidative stress and lysosomal destabilization; and mitochondrial dysfunction contributing to the cytotoxic response (Vandebriel and De Jong, 2012). Song et al. (2014) observed that $90 \mathrm{~nm} \mathrm{ZnO} \mathrm{NPs} \mathrm{at} \mathrm{a} \mathrm{concentration} \mathrm{of} 10$ $\mu \mathrm{g} / \mathrm{ml}$ decreases Caco- 2 cell viability, inhibits cell proliferation, enhance ROS generation along with SOD levels; signifying an oxidative stress response. In another study, MTT and LDH assays revealed the dose-dependent toxicity of $\mathrm{ZnO}$ NPs in Caco-2 cells (Kang et al., 2013).

\section{Silver Nanoparticles}

Silver nanoparticles are genotoxic, cytotoxic and even carcinogenic. The nano size of NPs allows them to cross the cellular barrier, leading to the formation of free radicals in the tissues and eventually leading to oxidative damage to the cells and tissues (Pradhan et al., 2015). In several in vitro studies, Ag NPs displayed toxicity through an oxidative stress-dependent mechanism as well as through oxidative stress-independent intracellular effects. It has been observed that the exposure of human lung fibroblasts and glioblastoma cells to 6-20 nm Ag NPs increased ROS production, induced mitochondrial injury and DNA damage and also induced G2/M phase cell cycle arrest (Rani et al., 2009). Similar toxicity has been observed in intestinal epithelial cells (Bohmert et al., 2012). In another study, Aueviriyavit et al. (2014) observed that $<100 \mathrm{~nm} \mathrm{Ag} \mathrm{NPs}$ can be internalized by cells with a dose-dependent decrease in cell viability, starting at $10 \mu \mathrm{g} / \mathrm{ml}$. Treatment with Ag NPs also induced activation of the stress-responsive gene Nrf2 and heme oxygenase-1 (HO-1). Recently, McCracken et al. (2016) also demonstrated that Ag NP-induced oxidative stress responses in intestinal epithelial cells. However, Song et al. (2014) reported that co-incubation of Caco-2 cells with $10 \mu \mathrm{g} / \mathrm{ml}$ of $90 \mathrm{~nm} \mathrm{Ag}$ NPs decreased the cell activity, but no induction of cell death was observed. In another study, Kumar (2015) reported that Ag NPs caused depolarization of $\alpha$-tubulin, a major component of microtubule, having adverse effect over the cellular structure and associated cytoskeleton of the cell.

Other nanomaterial(s), such as carbon NPs are also known to cause allergic inflammation and it has been reported that 
the single and multi-walled carbon nanotubes increased lung inflammation and allergen-specific IgE levels in mice sensitized to OVA egg allergen. In another study, multiwalled carbon nanotubes with preexisting inflammation increased airway fibrosis in mice with allergic asthma (He and Hwang, 2016).

Besides these concerns, application of some nanocomposites triggered concerns regarding their environmental impacts, due to their non-biodegradable nature. Therefore, eco-toxicity studies on nanoparticles are mandatory before their commercial applications. Overall, the existing reports regarding the toxicity of NPs are not in full agreement with each other and also not fully conclusive. There are ambiguous results leading to a vague situation regarding the toxicity of NP to human beings. Some reports indicate total metal migration, over others showing particle migration. An imperative conclusion from the above discussion is that if nanoparticles are completely covered or encapsulated by the host polymer matrix, then the probability of migration into food matrix is quite less. However, during un-intentional mechanical impact on the food contact surface, could alter the smooth properties or in case of cut edges or technically improperly manufactured polymer nanocomposite with nanoparticles may lead to its release. In lieu of the above, manufacturers should reassure fully incorporation of nanoparticles in films or molded articles (Stormer et al., 2017). Nevertheless, the available scientific data on toxicity or migration of NPs is still at infancy stage and additional meticulous analysis is required before their vast application. The ultimate fate and toxicity of nanomaterials in food packaging depend on the physiochemical characteristics and dosage. Safe application of nanotechnology to the food packaging requires systematic characterization and assessment in silico, in vitro, and in vivo. Altogether, taking into thought, a varied number of physical, chemical and biological factors, their absorption, distribution, metabolism, excretion and lastly their toxicity should be quantified and evaluated for risk assessment to consumers (He and Hwang, 2016).

\section{CONCLUDING REMARKS}

The quality of food items chiefly rely over their perishability. Perishable foods require ambient temperature to maintain quality and freshness during transit and storage. Monitoring the extent to which perishable foods encounter degradation promoting factors chiefly, oxygen, light and ethylene can control perishability. Food package and the packaging material involved

\section{REFERENCES}

Adame, D., and Beall, G. W. (2009). Direct measurement of the constrained polymer region in polyamide/clay nanocomposites and the implications for gas diffusion. Appl. Clay Sci. 42, 545-552. doi: 10.1016/j.clay.2008.03.005

Advantage Magazine (2004). Nanotechnology and Food Packaging. Available inline at: http://www.azonano.com/Details.asp?ArticleID $=857$

Ahmed, T. A., and Aljaeid, B. M. (2016). Preparation, characterization, and potential application of chitosan, chitosan derivatives, and chitosan metal play an important and decisive role in food quality and shelf life. Packaging chiefly influences the barrier properties to form an irrefutable food environment. The dawn of nanotechnology has further opened up new avenues and technological advancement possibilities in food packaging area. Linking of nanoparticles to polymer to fabricate nanomaterial packaging potentiates routine packaging with enhanced barrier properties, mechanical and thermal strength, flexibility and stability. Time-consuming quality-control analysis as well as consumer technical illiteracy is another key problem surfacing the food industry. Novel nanopackaging systems (Improved/Active/Intelligent packaging) have potential to serve as an important tool to overcome existing packaging challenges with consumer and industrialist satisfaction. It is anticipated that conventional packaging will be thoroughly replaced with multifunctional smart or active packaging. Nano-structured materials put a check to microbial invasion, assuring microbial food safety. Additionally, nanosensors alert and warn consumers regarding the safety and accurate nutritional status of the packaged food. Several corporations have entered in this area with introduction of new packaging systems with updated technology. However, being a young branch, gaps in knowledge exists, leaving ample questions to the scientific community; mainly concerning its toxicity and ecotoxicity. Concerns regarding nanoparticles migration to packaged foodstuffs has been raised, however, migration assays and risk assessment are still not conclusive. Undefined toxicity, scarcity of supportive clinical trials data and risk assessment studies limits the application of nanomaterial in the food packaging sector. Lastly, for the successful implementation of nanotechnologies at gigantic scale, consumer's approval is mandatory. Both benefits and risks assessment should be acknowledged undoubtedly. Accredited research bodies should come forward with appropriate labeling and set down common regulations that boost the consumer acceptability. Government agencies should come forward and work in co-ordinance with each other to tackle this issue sensibly and gallantly and make a way for developing world. Legislation and strategies should be framed prudently for the sake of civilization concerning the management and application of nanomaterial in food packaging systems.

\section{AUTHOR CONTRIBUTIONS}

CS and RD have contributed equally to this review work. NR helped in updating the manuscript. HP assisted in compilation and proper editing of this review. 
Arora, A., and Padua, G. W. (2010). Review: nanocomposites in food packaging. J. Food Sci. 75, R43-R49. doi: 10.1111/j.1750-3841.2009.01456.x

Arora, D., Sharma, N., Sharma, V., Abrol, V., Shankar, R., and Jaglan, S. (2016). An update on polysaccharide-based nanomaterials for antimicrobial applications. Appl. Microbiol. Biotechnol. 100, 2603-2615. doi: 10.1007/s00253-016-7315-0

Aschberger, K., Micheletti, C., Sokull-Klüttgen, B., and Christensen, F. M. (2011). Analysis of currently available data for characterising the risk of engineered nanomaterials to the environment and human health lessons learned from four case studies. Environ. Int. 37, 1143-1156. doi: 10.1016/j.envint.2011.02.005

Asgari, P., Moradi, O., and Tajeddin, B. (2014). The effect of nanocomposite packaging carbon nanotube base on organoleptic and fungal growth of Mazafati brand dates. Inter. Nano. Lett. 4, 1-5. doi: 10.1007/s40089-014-0098-3

Aueviriyavit, S., Phummiratch, D., and Maniratanachote, R. (2014). Mechanistic study on the biological effects of silver and gold nanoparticles in Caco-2 cells-induction of the Nrf2/HO-1 pathway by high concentrations of silver nanoparticles. Toxicol. Lett. 224, 73-83. doi: 10.1016/j.toxlet.2013.09.020

Avella, M., De Vlieger, J. J., Errico, M. E., Fischer, S., Vacca, P., and Volpe, M. G. (2005). Biodegradable starch/clay nanocomposite films for food packaging applications. Food Chem. 93, 467-474. doi: 10.1016/j.foodchem.2004.10.024

Belli, B. (2012). Eating Nano: Processed Foods and Food Packaging Already Contain Nanoparticles - Some of Which Could be Harmful to Our Health. The Environmental Magazine Website. Available online at: http://www.emagazine.com/includes/print-article/magazine/9623/

Biji, K. B., Ravishankar, C. N., Mohan, C. O., and Gopal, T. K. S. (2015). Smart packaging systems for food applications: a review. J. Food Sci. Technol. 52, 6125-6135. doi: 10.1007/s13197-015-1766-7

Bikiaris, D. N., and Triantafyllidis, K. S. (2013). HDPE/Cu-nanofiber nanocomposites with enhanced antibacterial and oxygen barrier properties appropriate for food packaging applications. Mater. Lett. 93, 1-4. doi: 10.1016/j.matlet.2012.10.128

Bohmert, L., Niemann, B., Thunemann, A. F., and Lampen, A. (2012). Cytotoxicity of peptide-coated silver nanoparticles on the human intestinal cell line Caco-2. Arch. Toxicol. 86, 1107-1115. doi: 10.1007/s00204-012-0840-4

Borchert, N. B., Kerry, J. P., and Papkovsky, D. B. (2013). $\mathrm{CO}_{2}$ sensor based on Ptporphyrin dye and FRET scheme for food packaging applications. Sens. Actuat. B 176, 157- 165. doi: 10.1016/j.snb.2012.09.043

Bouwmeester, H., Dekkers, S., Noordam, M., Hagens, W., Bulder, A., de Heer, C., et al. (2007). Health Impact of Nanotechnologies in Food Production. RIKILT/RIVM Report 2007.014. Available online at: http://edepot.wur.nl/120669

Bouwmeester, H., Dekkers, S., Noordam, M., Hagens, W., Bulder, A., de Heer, C., et al. (2009). Review of health safety aspects of nanotechnologies in food production. Regul. Toxicol. Pharmacol. 53, 52-62. doi: 10.1016/j.yrtph.2008.10.008

Bracho, D., Dougnac, V. N., Palza, H., and Quijada, R. (2012). Fictionalization of silica nanoparticles for polypropylene nanocomposite applications. J. Nanomater. 2012:263915. doi: 10.1155/2012/263915

Brandelli, A., Brum, L. F. W., and dos Santos, J. H. Z. (2017). Nanostructured bioactive compounds for ecological food packaging. Environ. Chem. Lett. 15, 193-204. doi: 10.1007/s10311-017-0621-7

Bratovcic, A., Odobašić, A., Ćatić, S., and Šestan, I. (2015). Application of polymer nanocomposite materials in food packaging. Croat. J. Food Sci. Technol. 7, 86-94. doi: 10.17508/CJFST.2015.7.2.06

Brown, E. M., Paunesku, T., Wu, A., Thurn, K. T., Haley, B., Clark, J., Priester, T., et al. (2008). Methods for assessing DNA hybridization of peptide nucleic acid-titanium dioxide nanoconjugates. Anal. Biochem. 383, 226-235. doi: $10.1016 /$ j.ab.2008.08.020

Bumbudsanpharoke, N., and Ko, S. (2015). Nano-food packaging: an overview of market, migration research, and safety regulations. J. Food Sci. 80, R910-R923. doi: 10.1111/1750-3841.12861

Burdock, G. A. (2007). Safety assessment of hydroxypropyl methylcellulose as a food ingredient. Food Chem Toxicol. 45, 2341-2351. doi: 10.1016/j.fct.2007.07.011

Busolo, M. A., and Lagaron, J. M. (2012). Oxygen scavenging polyolefin nanocomposite films containing an iron modified kaolinite of interest in active food packaging applications. Innov. Food Sci. Emerg. Technol. 16, 211-217. doi: $10.1016 /$ j.ifset.2012.06.008
Busolo, M. A., Fernandez, P., Ocio, M. J., and Lagaron, J. M. (2010). Novel silverbased nanoclay as an antimicrobial in polylactic acid food packaging coatings. Food Addit. Contam. 27, 1617-1626. doi: 10.1080/19440049.2010.506601

Cardenas, G., Díaz, J., Meléndrez, M., Cruzat, C., and Cancino, A. G. (2009). Colloidal $\mathrm{Cu}$ nanoparticles/chitosan composite film obtained by microwave heating for food package applications. Polym. Bull 62, 511-524. doi: 10.1007/s00289-008-0031-x

Carrero-Sánchez, J. C., Elías, A. L., Mancilla, R., Arrellín, G., Terrones, H., Laclette, J. P., et al. (2006). Biocompatibility and toxicological studies of carbon nanotubes doped with nitrogen. Nano Lett. 6, 1609-1616. doi: $10.1021 / \mathrm{nl} 060548 \mathrm{p}$

Cavaliere, E., De Cesari, S., Landini, G., Riccobono, E., Pallecchi, L., et al. (2015). Highly bactericidal Ag nanoparticle films obtained by cluster beam deposition. nanomedicine: nanotechnology. Biol. Med. 11, 1417-1423. doi: 10.1016/j.nano.2015.02.023

CDC (2011). Estimates of Foodborne illness in the United States. Available online at: https://www.cdc.gov/foodborneburden/index.html

Ce, N., Norena, C. P. Z., and Brandelli, A. (2012). Antimicrobial activity of chitosan films containing nisin, peptide P34, and natamycin. CyTA J. Food 10, 21-26. doi: 10.1080/19476337.2010.537371

Cerrada, M. L., Serrano, C., Sánchez-Chaves, M., Fernández-García, M., Fernández-Martín, F., and de Andrés, A. (2008). Self-sterilized EVOH$\mathrm{TiO}_{2}$ nanocomposites: effect of $\mathrm{TiO}_{2}$ content on biocidal properties. Adv. Funct. Mater. 18, 1949-1960. doi: 10.1002/adfm.200701068

Chalew, T. E. A., and Schwab, K. J. (2013). Toxicity of commercially available engineered nanoparticles to Caco-2 and SW480 human intestinal epithelial cells. Cell Biol. Toxicol. 29, 101-116. doi: 10.1007/s10565-013-9241-6

Chang, P. R., Jian, R., Yu, J., and Ma, X. (2010). Starch-based composites reinforced with novel chitin nanoparticles. Carbohydr. Polym. 80, 420-425. doi: 10.1016/j.carbpol.2009.11.041

Chatterjee, A. K., Chakraborty, R., and Basu, T. (2014). Mechanism of antibacterial activity of copper nanoparticles. Nanotechnology 25:135101. doi: 10.1088/0957-4484/25/13/135101

Chaudhry, Q., and Castle, L. (2011). Food applications of nanotechnologies: an overview of opportunities and challenges for developing countries. Trends Food Sci. Tech. 22, 595-603. doi: 10.1016/j.tifs.2011.01.001

Chaudhry, Q., Scotter,M., Blackburn, J., Ross, B., Boxall, A., Castle, L., et al. (2008). Applications and implications of nanotechnologies for the food sector. Food Addit. Contam. 25, 241-258. doi: 10.1080/02652030701744538

Chawengkijwanich, C., and Hayata, Y. (2008). Development of $\mathrm{TiO}_{2}$ powdercoated food packaging film and its ability to inactivate Escherichia coli in vitro and in actual test. Int. J. Food Microbiol. 123, 288-292. doi: 10.1016/j.ijfoodmicro.2007.12.017

Chen, W., Wang, X., Tao, Q., Wang, J., Zheng, Z., and Wang, X. (2013). Lotus-like paper/paperboard packaging prepared with nanomodified overprint varnish. Appl. Surf. Sci. 266, 319-325. doi: 10.1016/j.apsusc.2012.12.018

Chen, X., and Mao, S. S. (2006). Synthesis of titanium dioxide $\left(\mathrm{TiO}_{2}\right)$ nanomaterials. J. Nanosci. Nanotechnol. 6, 906-925. doi: 10.1002/ chin. 200629213

Chirayil, C. J., Mathew, L., and Thomas, S. (2014). Review of recent research in nano cellulose preparation from different lignocellulosic fibers. Rev. Adv. Mater. Sci. 37, 20-28

Chithrani, B. D., Ghazani, A. A., and Chan, W. C. (2006). Determining the size and shape dependence of gold nanoparticle uptake into mammalian cells. Nano Lett. 6, 662-668. doi: 10.1021/nl052396o

Cioffi, N., Torsi, L., Ditaranto, N., Tantillo, G., Ghibelli, L., Sabbatini, L., et al. (2005). Copper nanoparticle/polymer composites with antifungal and bacteriostatic properties. Chem. Mater. 17, 5255-5262. doi: 10.1021/cm0505244

Cooper, T. A. (2013). "Developments in plastic materials and recycling systems for packaging food, beverages and other fast-moving consumer goods," in Trends in Packaging of Food, Beverages and Other Fast-Moving Consumer Goods (FMCG): Markets, Materials and Technologies, ed N. Farmer N (Philadelphia, PA: Woodhead Publishing Limited).

Costa, C., Conte, A., Buonocore, G. G., and Del, N. M. A. (2011). Antimicrobial silver-montmorillonite nanoparticles to prolong the shelf life of fresh fruit salad. Int. J. Food Microbiol. 148, 164-167. doi: 10.1016/j.ijfoodmicro.2011.05.018 
Costa, C., Conte, A., Buonocore, G. G., Lavorgna, M., and Del, N. M. A. (2012). Calcium-alginate coating loaded with silver montmorillonite nanoparticles to prolong the shelf-life of fresh-cut carrots. Food Res. Inter. 48, 164-169. doi: 10.1016/j.foodres.2012.03.001

Cozmuta, A. M., Peter, A., Cozmuta, L. M., Nicula, C., Crisan, L., Baia, L., et al. (2015). Active packaging system based on $\mathrm{Ag} / \mathrm{TiO}_{2}$ nanocomposite used for extending the shelf life of bread. Chem. Microbiol. Investig. Packag. Technol. Sci. 28, 271-284. doi: 10.1002/pts.2103

Cubukcu, M., Timurb, S., and Anik, U. (2007). Examination of performance of glassy carbon paste electrode modified with gold nanoparticle and xanthine oxidase for xanthine and hypoxanthine detection. Talanta 74, 434-439. doi: 10.1016/j.talanta.2007.07.039

Cushen, M., Kerry, J., Morris, M., Cruz-Romero, M., and Cummins, E. (2012). Nanotechnologies in the food industry-Recent developments, risks and regulation. Trends Food Sci. Technol. 24, 30-46. doi: 10.1016/j.tifs.2011.10.006

Cyras, V. P., Manfredi, L. B., Ton-That, M. T., and Vazquez, A. (2008). Physical and mechanical properties of thermoplastic starch/montmorillonite nanocomposite films. Carbohydr. Polym. 73, 55-63. doi: 10.1016/j.carbpol.2007.11.014

Dalmas, F., Cavaille, J. Y., Gauthier, C., Chazeau, L., and Dendievel, R. (2007). Visco elastic behavior and electrical properties of flexible nanofiber filled polymer nanocomposites. Influence of processing conditions. Composites Sci. Technol. 67, 829-839. doi: 10.1016/j.compscitech.2006.01.030

Damm, C., Munstedt, H., and Rosch, A. (2008). The antimicrobial efficacy of polyamide 6/silver-nano and microcomposites. Mater. Chem. Phys. 108, 61-66. doi: 10.1016/j.matchemphys.2007.09.002

Dandekar, P., Jain, R., Stauner, T., Loretz, B., Koch, M., Wenz, G., et al. (2012). A hydrophobic starch polymer for nanoparticle-mediated delivery of docetaxel. Macromol. Biosci. 12, 184-194. doi: 10.1002/mabi.201100244

Danie, K. J., Shivendu, R., Nandita, D., and Proud, S. (2013). Nanotechnology for tissue engineering: need, techniques and applications. J. Pharm. Res. 6, 200-204. doi: 10.1016/j.jopr.2013.02.021

de Azeredo, H. M. C. (2009). Nanocomposites for food packaging applications. Food Res. Int. 42, 1240-1253. doi: 10.1016/j.foodres.2009.03.019

de Azeredo, H. M. C., Mattoso, L. H. C., and McHugh, T. H. (2011). "Nanocomposites in food packaging-a review," in Advances in Diverse Industrial Applications of Nanocomposites, ed B. S. R. Reddy (InTech), 57-78.

De Moura, M. R., Aouada, F. A., Avena-Bustillos, R. J., McHugh, T. H., Krochta, J. M., and Mattoso, L. H. C. (2008). Improved barrier and mechanical properties of novel hydroxypropyl methylcellulose edible films with chitosan/tripolyphosphate nanoparticlses. J. Food Eng. 92, 448-453. doi: 10.1016/j.jfoodeng.2008.12.015

De Moura, M. R., Mattoso, L. H. C., and Zucolotto, V. (2012). Development of cellulose-based bactericidal nanocomposites containing silver nanoparticles and their use as active food packaging. J. Food Eng. 109, 520-524. doi: 10.1016/j.jfoodeng.2011.10.030

Dias, M. V., Nde, F. S., Borges, S. V., de Sousa, M. M., Nunes, C. A., de Oliveira, I. R., et al. (2013). Use of allyl isothiocyanate and carbon nanotubes in an antimicrobial film to package shredded, cooked chicken meat. Food Chem. 141, 3160-3166. doi: 10.1016/j.foodchem.2013.05.148

Dimitrijevica, M., Karabasila, N., Boskovica, M., Teodorovica, V., Vasileva, D., Djordjevicb, V., et al. (2015). Safety aspects of nanotechnology applications in food packaging. Procedia Food Sci. 5, 57-60. doi: 10.1016/j.profoo.2015.09.015

Duncan, T. V. (2011). Applications of nanotechnology in food packaging and food safety: barrier materials, antimicrobials and sensors. J. Colloid Interface Sci. 363, 1-24. doi: 10.1016/j.jcis.2011.07.017

Duran, N., and Marcato, P. D. (2013). Nanobiotechnology perspectives. Role of nanotechnology in the food industry: a review. Int. J. Food Sci. Technol. 48, 1127-1134. doi: 10.1111/ijfs. 12027

Echegoyen, Y. (2015). "Nano-developments for food packaging and labeling applications," in Nanotechnologies in Food and Agriculture, eds M. Rai, C. Ribeiro, L. Mattoso, and N. Duran (Springer International Publishing), $141-168$

Emamifar, A., Kadivar, M., Shahedi, M., and Solaimanian-Zad, S. (2011a). Effect of nanocomposite packaging containing $\mathrm{Ag}$ and $\mathrm{ZnO}$ on inactivation of Lactobacillus plantarum in orange juice. Food Control 22, 408-413. doi: 10.1016/j.foodcont.2010.09.011
Emamifar, A., Kadivar, M., Shahedi, M., and Soleimanian-Zad, S. (2011b). Evaluation of nanocomposites packaging containing $\mathrm{Ag}$ and $\mathrm{ZnO}$ on shelflife of fresh orange juice. Innov. Food Sci. Emerg. Technol. 11, 742-748. doi: 10.1016/j.ifset.2010.06.003

Esser, B., Schnorr, J. M., and Swager, T. M. (2012). Selective detection of ethylene gas using carbon nanotube-based devices: utility in determination of fruit ripeness. Angewandte Chemie 51, 5752-5756. doi: 10.1002/anie.201201042

Esthappan, S. K., Sinha, M. K., Katiyar, P., Srivastav, A., and Joseph, R. (2013). Polypropylene/zinc oxide nanocomposite fibers: morphology and thermal analysis. J. Polym. Mater. 30, 79-89.

Farhoodi, M. (2016). Nanocomposite materials for food packaging applications: characterization and safety evaluation. Food Eng. Rev. 8, 35-51. doi: 10.1007/s12393-015-9114-2

Fayaz, A. M., Balaji, K., Girilal, M., Kalaichelvan, P. T., and Venkatesan, R. (2009). Mycobased synthesis of silver nanoparticles and their incorporation into Sodium Alginate films for vegetable and fruit preservation. J. Agric. Food Chem. 57, 6246-6252. doi: 10.1021/jf900337h

Fernandez, A., Cava, D., Ocio, M. J., and Lagaron, J. M. (2008). Perspectives for biocatalysts in food packaging. Trends Food Sci. Technol. 19, 198-206. doi: 10.1016/j.tifs.2007.12.004

Fernandez, A., Picouet, P., and Lloret, E. (2010a). Reduction of the spoilagerelated microflora in absorbent pads by silver nanotechnology during modified atmosphere packaging of beef meat. Food Prot. 73, 2263-2269.

Fernandez, A., Picouet, P., and Lloret, E. (2010b). Cellulose-silver nanoparticle hybrid materials to control spoilage-related microflora in absorbent pads located in trays of fresh-cut melon. Int. J. Food Microbiol. 142, 222-228. doi: 10.1016/j.ijfoodmicro.2010.07.001

Fernandez, A., Soriano, E., Lopez-Carballo, G., Picouet, P., Lloret, E., Gavara, R., et al. (2009). Preservation of aseptic conditions in absorbent pads by using silver nanotechnology. Food Res. Inter. 42, 1105-1112. doi: 10.1016/j.foodres.2009.05.009

Fortunati, E., Peltzer, M., Armentano, I., Jimenez, A., and Kenny, J. M. (2013a). Combined effects of cellulose nanocrystals and silver nanoparticles on the barrier and migration properties of PLA nanobiocomposites. J. Food Eng. 118, 117-124. doi: 10.1016/j.jfoodeng.2013.03.025

Fortunati, E., Puglia, D., Luzi, F., Santulli, C., Kenny, J. M., and Torre, L. (2013b). Binary PVA bio-nanocomposites containing cellulose nanocrystals extracted from different natural sources: part I. Carbohydr. Polym. 97, 825-836. doi: 10.1016/j.carbpol.2013.03.075

Fuertes, G., Soto, I., Carrasco, R., Vargas, M., Sabattin, J., and Lagos, C. (2016). Intelligent packaging systems: sensors and nanosensors to monitor food quality and safety. J. Sensors. 2016:8. doi: 10.1155/2016/4046061

Fujishima, A., Rao, T. N., and Tryk, D. A. (2000). Titanium dioxide photocatalysis. J. Photochem. Photobiol. Phytochem Rvw. 1, 1-21. doi: 10.1016/S1389-5567(00)00002-2

Gammariello, D., Conte, A., Buonocore, G. G., and Del, N. M. A. (2011). Bio-based nanocomposite coating to preserve quality of Fior di latte cheese. J. Dairy Sci. 94, 5298-5304. doi: 10.3168/jds.2011-4161

Gardner, D. J., Oporto, G. S., Mills, R., and Azizi Samir, M. A. S. (2008). Adhesion and gel mineralisation of cellulose nanorod nematic suspensions. J. Mater. Chem. 13, 696-699. doi: 10.1163/156856108X295509

Ghaderi, M., Mousavi, M., and Labbafi, M. (2014). All-cellulose nanocomposite film made from bagasse cellulose nanofibers for food packaging application, Carbohydr Polym. 104, 59-65. doi: 10.1016/j.carbpol.2014.01.013

Ghanbarzadeh, B., Oleyaei, S. A., and Almasi, H. (2015). Nano-structured materials utilized in biopolymer based plastics for food packaging applications. Crit. Rev. Food Sci. Nutr. 55, 1699-1723. doi: 10.1080/10408398.2012. 731023

Giles, E. L., Kuznesof, S., Clark, B., Hubbard, C., and Frewer, L. J. (2015). Consumer acceptance of and willingness to pay for food nanotechnology: a systematic review. J. Nanopart Res. 17:467. doi: 10.1007/s11051-015-3270-4

Gnach, A., and Bednarkiewicz, A. (2012). Lanthanide-doped upconverting nanoparticles: merits and challenges. Nano Tod. 7, 532-563. doi: 10.1016/j.nantod.2012.10.006

Gopinath, S., and Sugunan, S. (2007). Enzymes immobilized on montmorillonite $\mathrm{K} 10$ : effect of adsorption and grafting on the surface properties and the enzyme activity. Appl. Clay Sci. 35, 67-75. doi: 10.1016/j.clay.2006.04.007 
Gupta, N., Fischer, A. R. H., and Frewer, L. J. (2011). Socio-psychological determinants of public acceptance of technologies: a review. Public Underst. Sci. 21, 782-795. doi: 10.1177/0963662510392485

Gutierrez, T. J., Ponce, A. G., and Alvarez, A. V. (2017). Nano-clays from natural and modified montmorillonite with and without added blueberry extract for active and intelligent food nanopackaging materials. Mater. Chem. Phys. 194, 283-292. doi: 10.1016/j.matchemphys.2017.03.052

Gutierrez-Tauste, D., Domenech, X., Casan -Pastor, N., and Ayllon, J. A. (2007). Characterization of methylene blue/TiO2 hybrid thin films prepared by the liquid phase deposition (LPD) method: application for fabrication of lightactivated colorimetric oxygen indicators. J. Photochem. Photobiol. A 187, 45-52. doi: 10.1016/j.jphotochem.2006.09.011

Ham, M., Kim, J. C., and Chang, J. H. (2013). Thermal property, morphology, optical transparency, and gas permeability of PVA/SPT nanocomposite films and equi-biaxial stretching films. Polym. Korea 37, 579-586. doi: 10.7317/pk.2013.37.5.579

Hasim, S., Cruz-Romero, M. C., Cummins, E., Kerry, J. P., and Morris, M. P. (2015). The potential use of a layer-by-layer strategy to develop LDPE antimicrobial films coated with silver nanoparticles for packaging applications. J. Colloid Interface Sci. 461, 239-248 doi: 10.1016/j.jcis.2015.09.021

He, X., and Hwang, H. M. (2016). Nanotechnology in food science: functionality, applicability, and safety assessment. J. Food Drug Anal. 24, 671-681. doi: 10.1016/j.jfda.2016.06.001

Hong, W., Huang, L., Wang, H., Qu, J., Guo, Z., Xie, C., et al. (2010). Development of an up-converting phosphor technology-based 10- channel lateral flow assay for profiling antibodies against Yersinia pestis. J. Microbiol. Methods, 83, 133-140. doi: 10.1016/j.mimet.2010.08.005

Huang, J. Y., Li, X., and Zhou, W. (2015). Safety assessment of nanocomposite for food packaging application. Trends Food Sci. Technol. 45, 187-199. doi: $10.1016 /$ j.tifs.2015.07.002

Janjarasskul, T., and Suppakul, P. (2016). Active and intelligent packaging: the indication of quality and safety. Crit. Rev. Food Sci. Nutr. 19:0. doi: 10.1080/10408398.2016.1225278

Jia, X., Li, Y., Cheng, Q., Zhang, S., and Zhang, B. (2007). Preparation and properties of poly(vinyl alcohol)/silica nanocomposites derived from copolymerization of vinyl silica nanoparticles and vinyl acetate. Eur. Polym. J. 43, 1123-1131. doi: 10.1016/j.eurpolymj.2007.01.019

Jin, T., Sun, D., Su, J. Y., Zhang, H., and Sue, H. J. (2009). Antimicrobial efficacy of zinc oxide quantum dots against Listeria monocytogenes, Salmonella enteritidis, and Escherichia coli O157:H7. J. Food Sci. 74, 46-52. doi: 10.1111/j.1750-3841.2008.01013.x

Jones, N., Ray, B., Ranjit, K. T., and Manna, A. C. (2008). Antibacterial activity of $\mathrm{ZnO}$ nanoparticle suspensions on a broad spectrum of microorganisms. FEMS Microbiol. Lett. 279, 71-76. doi: 10.1111/j.1574-6968.2007.01012.x

Jung, J., Puligundla, P., and Ko, S. (2012). Proof-of-concept study of chitosanbased carbon dioxide indicator for food packaging applications. Food Chem. 135, 2170-2174. doi: 10.1016/j.foodchem.2012.07.090

Kang, S., Pinault, M., Pfefferle, L. D., and Elimelech, M. (2007). Singlewalled carbon nanotubes exhibit strong antimicrobial activity. Langmuir 23:8670-8673. doi: 10.1021/la701067r

Kang, T., Guan, R., Chen, X., Song, Y., Jiang, H., and Zhao, J. (2013). In vitro toxicity of different-sized $\mathrm{ZnO}$ nanoparticles in Caco-2 cells. Nanoscale Res. Lett. 8:496. doi: 10.1186/1556-276X-8-496

Kerry, J. P., Ogrady, M. N., and Hogan, S. A. (2006). Past, current and potential utilisation of active and intelligent packaging systems for meat and muscle-based products: a review. Meat Sci. 74, 113-130. doi: 10.1016/j.meatsci.2006.04.024

Khalaf, H. H., Sharoba, A. M., El-Tanahi, H. H., and Morsy, M. K. (2013). Stability of antimicrobial activity of pullulan edible films incorpo-rated with nanoparticles and essential oils and their impact on turkey deli meat quality. J. Food Dairy Sci. 4, 557-573.

Kim, J. Y., Han, S., and Hong, S. (2008). Effect of modified carbon nanotube on the properties of aromatic polyester nanocomposites. Polymer 49, 3335-3345. doi: $10.1016 /$ j.polymer.2008.05.024

Kim, Y. R., Lee, E. J., Park, S. H., Kwon, H. J., An, S. S., Song, S. W., et al. (2014). Comparative analysis of nanotechnology awareness in consumers and experts in South Korea. Int. J. Nanomedicine 15, 21-27. doi: 10.2147/IJN.S57921
Kim, Y. S., Kim, J. S., Cho, H. S., Rha, D. S., Kim, J. M., Park, J. D., et al. (2008). Twenty eight-day oral toxicity, genotoxicity, and gender-related tissue distribution of silver nanoparticles in Sprague-Dawley rats. Inhal. Toxicol. 20, 575-583. doi: 10.1080/08958370701874663

Koeneman, B. A., Zhang, Y., Westerhoff, P., Chen, Y., Crittenden, J. C., and Capco, D. J. (2010). Toxicity and cellular responses of intestinal cells exposed to titanium dioxide. Cell Biol. Toxicol. 26, 225-238. doi: 10.1007/s10565-009-9132-z

Koh, H. C., Park, J. S., Jeong, M. A., Hwang, H. Y., Hong, Y. T., Ha, S. Y. et al. (2008). Preparation and gas permeation properties of biodegradable polymer/layered silicate nanocomposite membranes. Desalination 233, 201-209. doi: 10.1016/j.desal.2007.09.043

Kong, H., Song, J., and Jang, J. (2010). Photocatalytic antibacterial capabilities of $\mathrm{TiO}(2)$-biocidal polymer nanocomposites synthesized by a surfaceinitiated photopolymerization. Environ. Sci. Technol. 44, 5672-5676. doi: $10.1021 /$ es 1010779

Kristo, E., and Biliaderis, C. G. (2007). Physical properites of starch nanocrystal reinforced pullulan films. Carbohydr. Polym. 68, 146-158. doi: 10.1016/j.carbpol.2006.07.021

Kubacka, A., Diez, M. S., Rojo, D., Bargiela, R., Ciordia, S., Zapico, I., et al. (2014). Understanding the antimicrobial mechanism of $\mathrm{TiO}_{2}$-based nanocomposite films in a pathogenic bacterium. Sci. Rep. 4:4134. doi: 10.1038/srep04134

Kumar, L. Y. (2015). Role and adverse effects of nanomaterials in food technology. J. Toxicol. Health. 2, 1-11. doi: 10.7243/2056-3779-2-2

Kumar, N., and Kumbhat, S. (2016). Essentials in Nanoscience and Nanotechnology. John Wiley \& Sons.

Kumar, R., and Munstedt, H. (2005). Silver ion release from antimicrobial polyamide/silver composites. Biomaterials 26, 2081-2088. doi: 10.1016/j.biomaterials.2004.05.030

Kuswandi, B. (2017). Environmental friendly food nano-packaging. Environ. Chem. Lett. 15, 205-221. doi: 10.1007/s10311-017-0613-7

Kuswandi, B., Jayus, Restanty, A., Abdullah, A., Heng, L. Y., and Ahmad, M. (2012). A novel colorimetric food package label for fish spoilage based on polyaniline film. Food Cont. 25, 184-189. doi: 10.1016/j.foodcont.2011. 10.008

Lau, A. K. T., and Hui, D. (2002). The revolutionary creation of new advanced Materials -carbon nanotube composites. Compos. B Eng. 33, 263-277. doi: 10.1016/S1359-8368(02)00012-4

Lee, S. K., Sheridan, M., and Mills, A. (2005). Novel UV-activated colorimetric oxygen indicator. Chem. Mater. 17, 2744-2751. doi: 10.1021/cm0403863

Lee, Y., Kim, D., Seo, J., Han, H., and Khan, S. B. (2013). Preparation and characterization of poly (propylene carbonate)/exfoliated graphite nanocomposite films with improved thermal stability, mechanical properties and barrier properties. Polym. Int. 62, 1386-1394. doi: 10.1002/pi.4434

Li, Q., Mahendra, S., Lyon, D. Y., Brunet, L., Liga, M. V., Li, D., et al. (2008). Antimicrobial nanomaterials for water disinfection and microbial control: potential applications and implications. Water Res. 42, 4591-4602. doi: 10.1016/j.watres.2008.08.015

Li, R., Liu, C. H., Ma, J., Yang, Y. J., and Wu, H. X. (2011). Effect of orgtitanium phosphonate on the properties of chitosan films. Polym. Bull. 67, 77-89. doi: 10.1007/s00289-010-0404-9

Li, S. C., and Li, Y. N. (2010). Mechanical and antibacterial properties of modified nano- $\mathrm{ZnO} /$ high-density polyethylene composite films with a low doped content of nano- ZnO, J. Appl. Polym. Sci. 116, 2965-2969. doi: 10.1002/app.31802

Li, X., Li, W., Jiang, Y., Ding, Y., Yun, I., Tang, Y., et al. (2011). Effect of nanoZnO-coated active packaging on quality of fresh-cut 'Fuji' apple. Int. J. Food Sci. Technol. 46, 1947-1955. doi: 10.1111/j.1365-2621.2011.02706.x

Li, X., Xing, Y., Jiang, Y., Ding, Y., and Li, W. (2009). Antimicrobial activities of $\mathrm{ZnO}$ powder-coated PVC film to inactivate food pathogens. Int. J. Food Sci. Technol. 44, 2161-2168. 10.1111/j.1365-2621.2009.02055.x

Liang, S.-S., Makamba, H., Huang, S.-Y., and and Chen, S.-H. (2006). Nanotitanium dioxide composites for the enrichment of phosphopeptides. J. Chromatogr. A. 1116, 38-45. doi: 10.1016/j.chroma.2006.03.012

Liao, F., Chen, C., and Subramanian, V. (2005). Organic TFTs as gas sensors for electronic nose applications. Sens Actuators B Chem. 107, 849-855. doi: $10.1016 / j . s n b .2004 .12 .026$ 
Lim, J. H., Park, J., Ahn, J. H., Jin, H. J., Hong, S., and Park, T. H. (2013). A peptide receptor-based bioelectronic nose for the real-time determination of seafood quality. Biosens. Bioelectron. 39, 244-249. doi: 10.1016/j.bios.2012.07.054

Lim, L. T. (2011). Active and Intelligent Packaging Materials. Comprehensive Biotechnology. Amsterdam:Elsevier.

Lima, M. M. D., and Borsali, R. (2004). Rod like cellulose microcrystals: structure, properties, and applications. Macromol. Rapid Commun. 25, 771-787. doi: 10.1002/marc. 200300268

Lin, N., Huang, J., and Dufresne, A. (2012). Preparation, properties and applications of polysaccharide nanocrystals in advanced functional nanomaterials: a review. Nanoscale 4, 3274-3294. doi: 10.1039/c2nr30260h

Lin, S., Chen, L., Huang, L., Cao, S., Luo, X., and Liu, K. (2015). Novel antimicrobial chitosan-cellulose composite films bioconjugated with silver nanoparticles. Ind. Crops Prod. 70:395-403. doi: 10.1016/j.indcrop.2015.03.040

Liu, S. F., Petty, A. R., Sazama, G. T., and Swager, T. M. (2015). Singlewalled carbon nanotube/metalloporphyrin composites for the chemiresistive detection of amines and meat spoilage. Angew. Chem. Int. Ed. Engl. 54, 6554-6657. doi: 10.1002/anie.201501434

Lloret, E., Picouet, P., and Fernandez, A. (2012). Matrix effects on the antimicrobial capacity of silver based nanocomposite absorbing materials. LWT Food Sci. Technol. 49, 333-338. doi: 10.1016/j.lwt.2012.01.042

Lopez-Leon, T., Carvalho, E. L. S., Seijo, B., Ortega-Vinuesa, J. L., and Bastos-Gonzalez, D. (2005). Physicochemical characterization of chitosan nanoparticles: electrokinetic and stability behavior. J. Colloid Interface Sci. 283, 344-351. doi: 10.1016/j.jcis.2004.08.186

Lopez-Rubio, A., Gavara, R., and Lagaron, J. M. (2006). Bioactive packaging: turning foods into healthier foods through biomaterials. Trends Food Sci. Technol. 17, 567-575. doi: 10.1016/j.tifs.2006.04.012

Lotti, C., Isaac, C. S., Branciforti, M. C., Alves, R. M. V., Liberman, S., and Bretas, R. E. S. (2008). Rheological, mechanical and transport properties of blown films of high density polyethylene nanocomposites. Eur. Polym. J. 44, 1346-1357. doi: 10.1016/j.eurpolymj.2008.02.014

Love, S. A., Maurer-Jones, M. A., Thompson, J. W., Lin, Y. S., and Haynes, C. L. (2012). Assessing nanoparticle toxicity. Annu. Rev. Anal. Chem. 5, 181-205. doi: 10.1146/annurev-anchem-062011-143134

Lu, Y., Weng, L., and Zhang, L. (2004). Morphology and properties of soy protein isolate thermoplastics reinforced with chitin whiskers. Biomacromolecules 5, 1046-1051. doi: 10.1021/bm034516x

Luduena, L. N., Alvarez, V. A., and Vasquez, A. (2007). Processing and microstructure of PCL/clay nanocomposites. Mater. Sci. Eng. A. 121-129. doi: 10.1016/j.msea.2007.01.104

Macwan, D., Dave, P. N., and Chaturvedi, S. (2011). A review on nano- $\mathrm{TiO}_{2}$ sol-gel type syntheses and its applications. J. Mater. Sci. 46:3669-3686. doi: 10.1007/s10853-011-5378-y

Mahalik, N. P., and Nambiar, A. N. (2010). Trends in food packaging and manufacturing systems and technology. Trends Food Sci. Technol. 21, 117-128. doi: 10.1016/j.tifs.2009.12.006

Maisanaba, S., Pichardo, S., Puerto, M., Gutiérrez-Praena, D., Cameán, A. M., and Jos, A. (2015). Toxicological evaluation of clay minerals and derived nanocomposites: a review. Environ. Res. 138, 233-254. doi: 10.1016/j. envres.2014.12.024

Majid, I., Nayik, G. A., Dar, M. S., and Nanda, V. (2016). Novel food packaging technologies: innovations and future prospective. J. Saudi Society Agric. Sci. doi: 10.1016/j.jssas.2016.11.003

Malathi, A. N., Santhosh, K. S., and Nidoni, U. (2014). Recent trends of Biodegradable polymer: Biodegradable films for Food Packaging and application of Nanotechnology in Biodegradable Food Packaging. Curr. Trends Tech. Sci. 3, 74-79.

Maneerat, C., and Hayata, Y. (2006). Antifungal activity of $\mathrm{TiO}_{2}$ photocatalysis against Penicillium expansum in vitro and in fruit tests. Int. J. Food Microbiol. 107, 99-103. doi: 10.1016/j.ijfoodmicro.2005.08.018

Martinez-Abad, A., Lagaron, J. M., and Ocio, M. J. (2012). Development and characterization of silver-based antimicrobial ethylene-vinyl alcohol copolymer (EVOH) films for food-packaging applications. J. Agric. Food Chem. 60, 5350-5359. doi: 10.1021/jf300334z

Mastromatteo, M., Conte, A., Lucera, A., Saccotelli, M. A., Buonocore, G. G., Zambrini, A. V., et al. (2015). Packaging solutions to prolong the shelf life of
Fiordilatte cheese: bio-based nanocomposite coating and modified atmosphere packaging. LWT Food Sci. Technol. 60, 230-237. doi: 10.1016/j.lwt.2014.08.013

Maynor, M. S., Nelson, T. L., O’Sulliva, C., and Lavigne, J. J. (2007). A food freshness sensor using the multistate response from analyteinduced aggregation of a cross-reactive poly (thiophene). Org. Lett. 9, 3217-3220. doi: 10.1021/ol071065a

McCracken, C., Dutta, P., and Waldman, W. J. (2016). Critical assessment of toxicological effects of ingested nanoparticles. Environ. Sci. Nano. 3, 256-282. doi: 10.1039/C5EN00242G

Metak, A. M., and Ajaal, T. T. (2013). Investigation on polymer based nanosilver as food packaging materials. Int. J. Biol. Food Vet. Agric. Eng. 7, 772-777.

Metak, M. M. (2015). Effects of Nanocomposite Based Nano-Silver and NanoTitanium Dioxide on Food Packaging Materials. Int. J. Appl. Sci. Technol. 5, $26-40$

Mihindukulasuriya, S. D. F., and Lim, L. T. (2013). Oxygen detection using UV-activated electrospun poly (ethylene oxide) fibers encapsulated with $\mathrm{TiO}_{2}$ nanoparticles. J. Mater. Sci. 48, 5489-5498. doi: 10.1007/s10853-013-7343-4

Mihindukulasuriya, S. D. F., and Lim, L. T. (2014). Nanotechnology development in food packaging: a review. Trends Food Sci. Tech. 40, 149-167. doi: 10.1016/j.tifs.2014.09.009

Mills, A. (2005). Oxygen indicator and intelligent inks for packaging food. Chem. Soc. Rev. 34, 1003-1011. doi: 10.1039/b503997p

Mills, A., and Hazafy, D. (2009). Nanocrystalline $\mathrm{SnO}_{2}$-based, UVB-activated, colourimetric oxygen indicator. Sensor Actuat. B Chem. 36, 344-349. doi: 10.1016/j.snb.2008.12.048

Mirzadeh, A., and Kokabi, M. (2007). The effect of composition and draw-down ratio on morphology and oxygen permeability of polypropylene nanocomposite blown films. Eur. Polym. J. 43, 3757-3765. doi: 10.1016/j.eurpolymj.2007.06.014

Mittal, V. (2009). Polymer layered silicate nanocomposites: a review. Materials 2, 992-1057. doi: 10.3390/ma2030992

Moghadam, A. D., Omrani, E., Menezes, P. L., and Rohatgi, P. K. (2015) Mechanical and tribological properties of self-lubricating metal matrix nanocomposites reinforced by carbon nanotubes (CNTs) and grapheme - A Review. Compos. B Eng. 77, 402-420. doi: 10.1016/j.compositesb.2015.03.014

Momin, J. K., and Joshi, B. H. (2015). "Nanotechnology in foods," in Nanotechnologies in Food and Agriculture, eds M. Rai, C. Ribeiro, L. Mattoso, and N. Duran (Springer International Publishing), 3-24.

Montazer, M., and Harifi, T. (2017). "New approaches and future aspects of antibacterial food packaging: from nanoparticles coating to nanofibers and nanocomposites, with foresight to address the regulatory uncertainty," in Food Package, ed A. M. Grumezescu (Academic Press), 533-559.

Montazer, M., and Seifollahzadeh, S. (2011). Enhanced self-cleaning, antibacterial and UV protection properties of nano $\mathrm{TiO}_{2}$ treated textile through enzymatic pretreatment. Photochem. Photobiol. 87, 877-883. doi: 10.1111/j.1751-1097.2011.00917.x

Moos, P. J., Olszewski, K., Honeggar, M., Cassidy, P., Leachman, S., Woessner, D., et al. (2011). Responses of human cells to $\mathrm{ZnO}$ nanoparticles: a gene transcription study. Metallomics 3, 1199-1211. doi: 10.1039/c1mt00061f

Morones, J. R., Elechiguerra, J. L., Camacho, A., Holt, K., Kouri, J. B., Ramirez, J. T., et al. (2005). The bactericidal effect of silver nanoparticles. Nanotechnology 16, 2346-2353. doi: 10.1088/0957-4484/16/10/059

Motlagh, N. V., Mosavian, M. T. H., and Mortazavi, S. A. (2012). Effect of polyethylene packaging modified with silver particles on the microbial, sensory and appearance of dried barberry. Packag. Technol. Sci. 26, 39-49. doi: $10.1002 /$ pts.1966

Muller, C. M. O., Laurindo, B. J., and Yamashita, F. (2012).Composites of thermoplastic starch and nanoclays produced by extrusion and thermopressing.Carbohydr. Polym. 89, 504-510. doi: 10.1016/j.carbpol.2012.03.035

Murariu, M., Doumbia, A., Bonnaud, L., Dechief, A. L., Paint, Y., Ferreira, M., et al. (2011). High-performance polylactide/ZnO nanocomposites designed for films and fibers with special end-use properties. Biomacromolecules 12, 1762-1771. doi: 10.1021/bm2001445

Naicker, P. K., Cummings, P. T., Zhang, H., and Banfield, J. F. (2005). Characterization of titanium dioxide nanoparticles using molecular dynamics simulations. J. Phys. Chem. B. 109, 15243-15249. doi: 10.1021/jp050963q 
Nanocor (2008). Nanocor Product Lines. Available online at: http://www.nanocor.com/products.asp

Neethirajan, S., and Jayas, D. S. (2011). Nanotechnology for the food and bioprocessing industries. Food Bioprocess Technol. 4, 39-47. doi: 10.1007/s11947-010-0328-2

Nel, A. E., Mädler, L., Velegol, D., Xia, T., Hoek, E. M. V., Somasundaran, P., et al. (2009). Understanding biophysicochemical interactions at the nano-bio interface. Nat. Mater. 8, 543-557. doi: 10.1038/nmat2442

Niedbala, R. S., Feindt, H., Kardos, K., Vail, T., Burton, J., Bielska, B., et al. (2001). Detection of analytes by immunoassay using upconverting phosphor technology. Anal. Biochem. 293, 22-30. doi: 10.1006/abio.2001.5105

Ong, L. C., Ang, L. Y., Alonso, S., and Zhang, Y. (2014). Bacterial imaging with photostable upconversion fluorescent nanoparticles. Biomaterials 35, 2987-2998. doi: 10.1016/j.biomaterials.2013.12.060

Orsuwan, A., Shankar, S., Wang, L. F., Sothornvit, R., and Rhim, J. W. (2016). Preparation of antimicrobial agar/banana powder blend films reinforced with silver nanoparticles. Food Hydrocoll. 60, 476-485. doi: 10.1016/j.foodhyd.2016.04.017

Othman, S. H. (2014). Bio-nanocomposite materials for food packaging applications: types of biopolymer and nano-sized filler. Agr. Agr. Sci. Procedia 2, 296-303. doi: 10.1016/j.aaspro.2014.11.042

Panea, B. G., Ripoll, González, J., Fernández-Cuello, A., and Albert,í, P. (2013). Effect of nanocomposite packaging containing different proportions of $\mathrm{ZnO}$ and $\mathrm{Ag}$ on chicken breast meat quality. J. Food Eng. 123, 104-112. doi: 10.1016/j.jfoodeng.2013.09.029

Paul, D. R., and Robeson, L. M. (2008). Polymer nanotechnology: nanocomposites. Polymer 49, 3187-3204. doi: 10.1016/j.polymer.2008.04.017

Petchwattana, N., and Naknaen, P. (2015). Utilization of thymol as an antimicrobial agent for biodegradable poly(butylene succinate). Mater. Chem. Phys. 163, 369-375. doi: 10.1016/j.matchemphys.2015.07.052

Petchwattana, N., Covavisaruch, S., Wibooranawong, S., and Naknaen, P. (2016). Antimicrobial food packaging prepared from poly(butylene succinate) and zinc oxide. Measurement 93, 442-448. doi: 10.1016/j.measurement.2016. 07.048

Petersson, L., and Oksman, K. (2006). Biopolymer based nanocomposites: comparing layered silicates and microcrystalline cellulose as nanoreinforcement. Compos. Sci. Technol. 66, 2187-2196. doi: 10.1016/j.compscitech.2005.12.010

Picouet, P. A., Fernandez, A., Realini, C. E., and Lloret, E. (2014). Influence of PA6 nanocomposite films on the stability of vacuum-aged beef loins during storage in modified atmospheres. Meat Sci. 96, 574-580. doi: 10.1016/j.meatsci.2013.07.020

Podsiadlo, P., Choi, S. Y., Shim, B., Lee, J., Cuddihy, M., and Kotov, N. A. (2005). Molecularly engineered nanocomposites: layer-by-layer assembly of cellulose nanocrystals. Biomacromolecules 6, 2914-2918. doi: 10.1021/bm050333u

Pradhan, N., Singh, S., Ojha, N., Shrivastava, A., Barla, A., Rai, V., et al. (2015). Facets of nanotechnology as seen in food processing, packaging, and preservation industry. BioMed. Res. Int. 2015:17. doi: 10.1155/2015/365672

Prasad, P., and Kochhar, A. (2014). Active packaging in food industry: a review. J. Environ. Sci. Toxicol. Food Technol. 8, 1-7.

Prashantha, K., Soulestin, J., Lacrampe, M. F., Krawczak, P., Dupin, G., and Claes, M. (2009). Masterbatch-based multi-walled carbon nanotube filled polypropylene nanocomposites: assessment of rheological and mechanical properties. Compos. Sci. Technol. 69, 1756-1763. doi: 10.1016/j.compscitech.2008.10.005

Prateek, Thakur, V. K., and Gupta, R. K. (2016). Recent progress on ferroelectric polymer-based nanocomposites for high energy density capacitors: synthesis, dielectric properties, and future aspects. Chem. Rev. 116, 4260-4317. doi: $10.1021 /$ acs.chemrev.5b00495

Puligundla, P., Jung, J., and Ko, S. (2012). Carbon dioxide sensors for intelligent food packaging applications. Food Control 25, 328-333. doi: 10.1016/j.foodcont.2011.10.043

Qhobosheane, M., Santra, S., Zhang, P., and Tan, W. H. (2001). Biochemically functionalized silica nanoparticles. Analyst 126, 1274-1278. doi: $10.1039 / \mathrm{b} 101489 \mathrm{~g}$

Rafieian, F., and Simonsen, J. (2014). Fabrication and characterization of carboxylated cellulose nanocrystals reinforced glutenin nanocomposite. Cellulose 21, 4167-4180. doi: 10.1007/s10570-014-0305-4
Ramos, O. L., Fernandes, J. C., Silva, S. I., Pintado, M. E., and Malcata, F. X. (2012). Edible films and coatings from whey proteins: a review on formulation, and on mechanical and bioactive properties. Crit. Rev. Food Sci. Nutr. 52, 533-552. doi: $10.1080 / 10408398.2010 .500528$

Rani, P. V. A., Mun, G. L. K., Hande, M. P., and Valiyaveettil, S. (2009). Cytotoxicity and genotoxicity of silver nanoparticles in human cells. ACS Nano 3, 279-290. doi: $10.1021 / \mathrm{nn} 800596 \mathrm{w}$

Ranjan, S., Dasgupta, N., Chakraborty, A. R., Samuel, S. M., Ramalingam, C., Shanker, R., et al. (2014). Nanoscience and nanotechnologies in food industries: opportunities and research trends. J. Nanopart Res. 16:2464. doi: $10.1007 /$ s11051-014-2464-5

Ravichandran, R. (2010). Nanotechnology applications in food and food processing: innovative green approaches, opportunities and uncertainties for global market. Int. J. Green Nanotechnol. Biomed. 1, P72-P96, doi: 10.1080/19430871003684440

Rhim, J. W., and Ng, P. K. W. (2007). Natural biopolymer-based nanocomposite films for packaging applications. Crit. Rev. Food Sci. Nutr. 47, 411-433. doi: $10.1080 / 10408390600846366$

Rhim, J. W., Park, H. M., and Ha, C. S. (2013). Bio-nanocomposites for food packaging applications. Prog. Polym. Sci. 38, 1629-1652. doi: 10.1016/j.progpolymsci.2013.05.008

Rhim, J. W., Wang, L. F., Lee, Y., and Hong, S. I. (2014). Preparation and characterization of bio-nanocomposite films of agar and silver nanoparticles: laser ablation method. Carbohydr. Polym. 103, 456-465. doi: 10.1016/j.carbpol.2013.12.075

Rieger, K. A., Eagan, N. M., and Schiffman, J. D. (2015). Encapsulation of cinnamaldehyde into nanostructured chitosan films. J. Appl. Polym. Sci. 132:41739. doi: 10.1002/APP.41739

Robertson, G. L. (2012). Food Packaging: Principles and Practice. Boca Raton, FL: CRC Press.

Robertson, J. M. C., Robertson, P. K. J., and Lawton, L. A. (2005). A comparison of the effectiveness of $\mathrm{TiO} 2$ photocatalysis and UVA photolysis for the destruction of three pathogenic micro-organisms. J. Photochem. Photobiol. 175, 51-56. doi: 10.1016/j.jphotochem.2005.04.033

Robinson, D. K. R., and Morrison, M. J. (2010). Nanotechnologies for Food Packaging: Reporting the Science and Technology Research Trends. Observatory NANO. Available online at : http://www.observatorynano.eu/ project/filesystem/files/Food\%20Packaging\%20Report\%202010\%20DKR \%20Robinson.pdf.

Rossi, M., Passeri, D., Sinibaldi, A., Angjellari, M., Emanuela, T., Sorbo, A., et al. (2017). Nanotechnology for food packaging and food quality assessment. $A d v$. Food Nutr. Res. 82: 149-204. doi: 10.1016/bs.afnr.2017.01.002

Sadeghnejad, A., Aroujalian, A., Raisi, A., and Fazel, S. (2014). Antibacterial nano silver coating on the surface of polyethylene films using corona discharge. Surf. Coat. Tech. 245, 1-8. doi: 10.1016/j.surfcoat.2014.02.023

Salami-Kalajahi, M., Haddadi-Asl, V., and Roghani-Mamaqani, H. (2012). Study of kinetics and properties of polystyrene/silica nanocomposites prepared via in situ free radical and reversible addition-fragmentation chain transfer polymerizations. Sci. Iran. 19, 2004-2011. doi: 10.1016/j.scient.2012.10.003

Sanchez-Valdes, S., Ortega-Ortiz, H., Ramos-de Valle, L. F., Medellín-Rodríguez, F. J., and Guedea-Miranda, R. (2009). Mechanical and antimicrobial properties of multilayer films with a polyethylene/silver nanocomposite layer. J. Appl. Polym. Sci. 111, 953-962. doi: 10.1002/app.29051

Sandquist, D. (2013). New horizons for microfibrillated cellulose. Appita J. 66, $156-162$.

Sarkar, P., Choudhary, R., Panigrahi, S., Syed, I., Sivapratha, S., and Dhuma, C. V. (2017). Nano-inspired systems in food technology and packaging. Environ. Chem. Lett. doi: 10.1007/s10311-017-0649-8

Sawai, J. (2003). Quantitative evaluation of antibacterial activities of metallic oxide powders ( $\mathrm{ZnO}, \mathrm{MgO}$ and $\mathrm{CaO}$ ) by conductimetric assay. J. Microbiol. Meth. 54, 177-182. doi: 10.1016/S0167-7012(03)00037-X

Scallan, E., Hoekstra, R. M., Angulo, F. J., Tauxe, R.V., Widdowson, M.A., Roy, S.L. et al. (2011). Foodborne illness acquired in the United States major pathogens. Emerg. Infect. Dis. 17, 7-15. doi: 10.3201/eid1701.P11101

Schubbe, S., Schumann, C., Cavelius, C., Koch, M., Muller, T., and Kraegeloh, A. (2012). Size-dependent localization and quantitative evaluation of the intracellular migration of silica nanoparticles in Caco-2 cells. Chem. Mater. 24, 914-923. doi: $10.1021 / \mathrm{cm} 2018532$ 
Schuetz, M. R., Kalo, H., Linkebein, T., Groschel, A. H., Muller, A. H. E., Wilkie, C. A., et al. (2011). Shear stiff, surface modified, mica-like nanoplatelets: a novel filler for polymer nanocomposites. J. Mater. Chem. 21, 12110-12116. doi: 10.1039/C1JM11443C

Sevinc, B. A., and Hanley, L. (2010). Antibacterial activity of dental composites containing zinc oxide nanoparticles, J. Biomed.Mater.Res. Part B Appl. Biomater. 94, 22-31. doi: 10.1002/jbm.b.31620

Shan, D., Wang, Y., Xue, H., and Cosnier, S. (2009). Sensitive and selective xanthine amperometric sensors based on calcium carbonate nanoparticles. Sensors Actuat B Chem, 136, 510-515. doi: 10.1016/j.snb.2008.10.012

Shang, L., Nienhaus, K., and Nienhaus, G. U. (2014). Engineered nanoparticles interacting with cells: size matters. J. Nanobiotechnol. 12, 1-11. doi: 10.1186/1477-3155-12-5

Sharma, A. L., Singhal, R., Kumar, A., Rajesh Pande, K. K., and Malhotra, B. D. (2004). Immobilization of glucose oxidase onto electrochemically prepared poly (aniline-co-fluoroaniline) films. J. Appl. Polym. Sci. 91, 3999-4006. doi: 10.1002/app.13553

Sharma, V., Shukla, R. K., Saxena, N., Parmar, D., Das, M., and Dhawan, A. (2009). DNA damaging potential of zinc oxide nanoparticles in human epidermal cells. Toxicol. Lett. 185, 211-218. doi: 10.1016/j.toxlet.2009.01.008

Sheikh, F. A., Kanjawal, M. A., Saran, S., Chung, W. J., and Kim, H. (2011). Polyurethane nanofibers containing copper nanoparticles as future materials. Appl. Surf. Sci. 257, 3020-3026. doi: 10.1016/j.apsusc.2010.10.110

Shi, H., Magaye, R., Castranova, V., and Zhao, J. (2013). Titanium dioxide nanoparticles: a review of current toxicological data. Particle Fibre Toxicol. 10, 15. doi: 10.1186/1743-8977-10-15

Shi, L., Zhao, Y., Zhang, X., Su, H., and Tan, T. (2008). Antibacterial and antimildew behavior of chitosan/nano-TiO2 composite emulsion. Korean J. Chem. Eng. 25, 1434-1438. doi: 10.1007/s11814-008-0235-7

Silvestre, C., Duraccio, D., and Cimmino, S. (2011). Food packaging based on polymer nanomaterials. Prog. Polym. Sci. 36, 1766-1782. doi: 10.1016/j.progpolymsci.2011.02.003

Singh, R. P. (2000). "Scientific principles of shelf-life evaluation," in Shelf-life evaluation of foods, eds D. Man and A. Jones (Aspen Publication), 2-22.

Sirelkhatim, A., Mahmud, S., Seeni, A., Kaus, N. H. M., Ann, L. C., Bakhori, S. K. M., et al. (2015). Review on zinc oxide nanoparticles: antibacterial activity and toxicity mechanism. Nano Micro Lett. 7, 219-242. doi: 10.1007/s40820-015-0040-x

Smolander, M., Hurme, E., Koivisto, M., and Kivinen, S. (2004). Indicator. International Patent WO2004/102185 A1.

Smolkova, B., El Yamani, N., Collins, A. R., Gutleb, A. C., and Dusinska, M. (2015). Nanoparticles in food. Epigenetic changes induced by nanomaterials and possible impact on health. Food Chem. Toxicol. 77:64-73. doi: $10.1016 /$ j.fct.2014.12.015

Song, Y., Guan, R., Lyu, F., Kang, T., Wu, Y., and Chen, X. (2014). In vitro cytotoxicity of silver nanoparticles and zinc oxide nanoparticles to human epithelial colorectal adenocarcinoma (Caco-2) cells. Mutat. Res. 769, 113-118. doi: 10.1016/j.mrfmmm.2014.08.001

Souza, V. G. L., and Fernando, A. L. (2016). Nanoparticles in food packaging: biodegradability and potential migration to food-A review. Food Packaging Shelf Life 8, 63-70. doi: 10.1016/j.fpsl.2016.04.001

Soysal, C., Bozkurt, H., Dirican, E., Güçlü, M., Bozhüyük, E. D., Uslu, A. E., et al. (2015). Effect of antimicrobial packaging on physicochemical and microbial quality of chicken drumsticks. Food Control. 54, 294-299. doi: 10.1016/j.foodcont.2015.02.009

Stormer, A., Bott, J., Kemmer, D., and Franz, R. (2017). Critical review of the migration potential of nanoparticles in food contact plastics. Trends Food Sci. Technol. 63, 39-50. doi: 10.1016/j.tifs.2017.01.011

Svagan, A. J., Hedenqvist, M. S., and Berglund, L. (2009). Reduced water vapour sorption in cellulose nanocomposites with starch matrix. Compos. Sci. Technol. 69, 500-506. doi: 10.1016/j.compscitech.2008.11.016

Swain, S. K., Pradhan, A. K., and Sahu, H. S. (2013). Synthesis of gas barrier starch by dispersion of functionalized multiwalled carbon nanotubes. Carbohydr. Polym. 94, 663-668. doi: 10.1016/j.carbpol.2013.01.056

Tan, W., Zhang, Y., Szeto, Y. S., and Liao, L. (2008). A novel method to prepare chitosan/ montmorillonite nanocomposites in the presence of hydroxyl-aluminum olygomeric cations. Compos. Sci. Technol. 68, 2917-2921. doi: 10.1016/j.compscitech.2007.10.007
Tang, C., and Liu, H. (2008). Cellulose nanofiber reinforced poly (vinyl alcohol) composite film with high visible light transmittance. Compos. A Appl. Sci. Manuf. 39, 1638-1643. doi: 10.1016/j.compositesa.2008.07.005

Tarantini, A., Lanceleur, R., Mourot, A., Lavault, M. T., Casterou, G., Jarry, G., et al. (2015). Toxicity, genotoxicity and proinflammatory effects of amorphous nanosilica in the human intestinal Caco-2 cell line. Toxicol. In vitro 29, 398-407. doi: 10.1016/j.tiv.2014.10.023

Tian, E., Cui, L., Wang, J., Song, Y., and Jiang, L. (2009). Tough photonic crystals fabricated by photo cross linkage of latex spheres. Macromol. Rapid Commun. 30, 509-514. doi: 10.1002/marc.200800731

Tripathi, S., Mehrotra, G. K., and Dutta, P. K., (2009). Physicochemical and bioactivity of cross-linked chitosan-PVA film for food packaging applications. Int. J. Biol. Macromol. 45, 372-376. doi: 10.1016/j.ijbiomac.2009. 07.006

Trujillo, L. E., Ávalos, R., Granda,. S., Guerra, L. S., and País-Chanfrau, J. M. (2016). Nanotechnology applications for food and bioprocessing industries. Biol. Med 8:289. doi: 10.4172/0974-8369.1000289

Valizadeh, A., Mikaeili, H., Samiei, M., Farkhani, S. M., Zarghami, N., Kouhi, M., et al. (2012). Quantum dots: synthesis, bioapplications, and toxicity. Nanoscale Res. Lett. 7:480. doi: 10.1186/1556-276X-7-480

Vandebriel, R. J., and De Jong, W. H. (2012). A review of mammalian toxicity of ZnO nanoparticles. Nanotechnol. Sci. Appl. 5, 61-71. doi: 10.2147/NSA.S23932

Vanderroost, M., Ragaert, P., Devlieghere, F., and Meulenaer, B. D. (2014). Intelligent food packaging: The next generation. Trends Food Sci. Tech. 39, 47-62. doi: 10.1016/j.tifs.2014.06.009

Varela, J. A., Bexiga, M. G., Aberg, C., Simpson, J. C., and Dawson, K. A. (2012). Quantifying size-dependent interactions between fluorescently labeled polystyrene nanoparticles and mammalian cells. J. Nanobiotechnol. 10:39. doi: 10.1186/1477-3155-10-39

Vermeiren, L., Devlieghere, F., and Debevere, J. (2002). Effectiveness of some recent antimicrobial packaging concepts. Food Addit.Contam. 19, 163-171.

Vladimiriov, V., Betchev, C., Vassiliou, A., Papageorgiou, G., and Bikiaris, D. (2006). Dynamic mechanical and morphological studies of isotactic polypropylene/fumed silica nanocomposites with enhanced gas barrier properties. Compos. Sci. Technol. 66, 2935-2944. doi: 10.1016/j.compscitech.2006.02.010

Volpe, M. G., Stasio, M. D., Paolucci, M., and Moccia, S. (2015). "Polymers for food shelf-life extension," in Functional Polymers in Food Science From Technology to Biology Food Packaging, eds G. Cirillo, U. G. Spizzirri, and F. Iemma (Hoboken, NJ: John Wiley \& Sons, Inc.), 9-61.

Wang, B., and Sain, M. (2007). Isolation of nanofibers from soybean source and their reinforcing capability on synthetic polymers. Compos. Sci. Technol. 67, 2521-2527. doi: 10.1016/j.compscitech.2006.12.015

Watson, S. B., Gergely, A., and Janus, E. (2011). Where Is "Agronanotechnology" Heading in the United States and European Union? Nat. Resour. Environ. 26, $8-12$.

Weiss, J., Takhistov, P., and Mc Clements, D. J. (2006). Functional materials in food nanotechnology. J. Food Sci. 71, R107-R116. doi: 10.1111/j.1750-3841.2006.00195.x

Wesley, S. J., Raja, P., Raj, A. A., and Tiroutchelvamae, D. (2014). Review on nanotechnology applications in food packaging and safety. Int. J. Eng. Res. 3, 645-651. doi: 10.17950/ijer/v3s11/1105

Wiburanawong, S., Petchwattana, N., and Covavisaruch, S. (2014). Carvacrol as an antimicrobial agent for poly(butylene succinate): tensile properties and antimicrobial activity observations, Adv. Mater. Res. 931, 111-115. doi: 10. 4028/www.scientific.net/AMR.931-932.111

Wu, C. L., Zhang, M. Q., Rong, M. Z., and Friedrich, K. (2002). Tensile performance improvement of low nanoparticles filledpolypropylene composites. Compos. Sci. Technol. 62, 1327-1340. doi: 10.1016/S0266-3538(02)00079-9

Wu, T. S., Wang, K. X., Li, G. D., Sun, S. Y., Sun, J., and Chen, J. S. (2010). Montmorillonite-supported $\mathrm{Ag} / \mathrm{TiO}(2)$ nanoparticles: an efficient visiblelight bacteria photodegradation material. ACS Appl. Mater. Int. 2, 544-550. doi: 10.1021/am900743d

Xiao, L., Green, A. N. M., Haque, S. A., Mills, A., and Durrant, J. R. (2004). Light-driven oxygen scavenging by titania/polymer nanocomposite films. J. Photochem. Photobiol. A Chem. 162, 253-259. doi: 10.1016/j.nainr.2003.08.010 
Xiong, H. G., Tang, S. W., Tang, H. L., and Zou, P. (2008). The structure and properties of a starch-based biodegradable film. Carbohydr. Polym. 71, 263-268. doi: 10.1016/j.carbpol.2007.05.035

Yamamoto, O. (2001). Influence of particle size on the antibacterial activity of zinc oxide. Int. J. Inorg. Mater. 3, 643-646. doi: 10.1016/S1466-6049(01) 00197-0

Yang, L., and Li, Y. (2006). Simultaneous detection of Escherichia coli O157:H7 and Salmonella Typhimurium using quantum dots as fluorescence labels. Analyst 131, 394-401. doi: 10.1039/b510888h

Yang, M., Kostov, Y., and Rasooly, A. (2008). Carbon nanotubes based optical immunodetection of Staphylococcal Enterotoxin B (SEB) in food. Int. J. Food Microbiol. 2127, 78-83. doi: 10.1016/j.ijfoodmicro.2008.06.012

Yang, Y. X., Song, Z. M., Cheng, B., Xiang, K., Chen, X. X., Liu, J. H., et al. (2014). Evaluation of the toxicity of food additive silica nanoparticles on gastrointestinal cells. J. Appl. Toxicol. 34, 424-435. doi: 10.1002/jat.2962

Ye, S. Y., Tian, Q. M., Song, X. L., and Luo, S. C. (2009). Photoelectrocatalytic degradation of ethylene by a combination of $\mathrm{TiO} 2$ and activated carbon felts. J. Photochem. Photobiol. A Chem. 208, 27-35. doi: 10.1016/j.jphotochem.2009.08.001

Yoshida, T., Yoshioka, Y., Fujimura, M., Yamashita, K., Higashisaka, K., Morishita, Y., et al. (2011). Promotion of allergic immune responses by intranasallyadministrated nanosilica particles in mice. Nanoscale Res. Lett. 6, 1-6. doi: 10.1186/1556-276X-6-195

Youssef, A. M. (2013). Polymer nanocomposites as a new trend for packaging applications. Polym. Plast. Technol. Eng. 52, 635-660. doi: 10.1080/03602559.2012.762673

Youssef, A. M., Abdel-Aziz, M. S., and El-Sayed, S. M. (2014). Chitosan nanocomposite films based on Ag-NP and Au-NP biosynthesis by Bacillus subtilis as packaging materials. Int. J. Biol. Macromol. 69, 185-191. doi: 10.1016/j.ijbiomac.2014.05.047

Zaman, H. U., Hun, P. D., Khan, R. A., and Yoon, K. B. (2012). Morphology, mechanical, and crystallization behaviors of micro- and nano$\mathrm{ZnO}$ filled polypropylene composites. J. Reinf. Plast. Comp. 31, 323-329. doi: $10.1177 / 0731684411436126$
Zeng, H., Gao, C., Wang, Y., Watts, P. C. P., Kong, H., Cui, X., et al. (2006). In situ polymerization approach to multiwalled carbon nanotubes-reinforced nylon 1010 composites: mechanical properties and crystallization behavior. Polymer 47, 113-122. doi: 10.1016/j.polymer.2005.11.009

Zeng, J., Roberts, S., and Xia, Y. (2010). Nanocrystal-based time-temperature indicators. Chem. A Eur. J. 16, 12559-12563. doi: 10.1002/chem.201002665

Zhang, C., Yin, A. X., Jiang, R., Rong, J., Dong, L., Zhao, T., et al. (2013). Time-temperature indicator for perishable products based on kinetically programmable Ag overgrowth on Au nanorods. ACS Nano 7, 4561-4568. doi: $10.1021 / \mathrm{nn} 401266 \mathrm{u}$

Zhou, C. (2013). Theoretical analysis of double-microfluidic-channels photonic crystal fiber sensor based on silver nanowires. Opt. Commun. 288, 42-46. doi: 10.1016/j.optcom.2012.09.060

Zhou, X., Shin, E., Wang, K. W., and Bakis, C. E. (2004). Interfacial damping characteristics of carbon nanotube-based composites. Compos. Sci. Technol. 64, 2425-2437. doi: 10.1016/j.compscitech.2004.06.001

Zulian, L., Emilitri, E., Scavia, G., Botta, C., Colombo, M., and Destri, S. (2012). Structural iridescent tuned colors from self-assembled polymer opal surfaces. ACS Appl. Mater. Interfaces 4, 6071-6079. doi: 10.1021/am301709b

Conflict of Interest Statement: The authors declare that the research was conducted in the absence of any commercial or financial relationships that could be construed as a potential conflict of interest.

The reviewer FP and handling Editor declared their shared affiliation, and the handling Editor states that the process nevertheless met the standards of a fair and objective review.

Copyright (c) 2017 Sharma, Dhiman, Rokana and Panwar. This is an open-access article distributed under the terms of the Creative Commons Attribution License (CC $B Y)$. The use, distribution or reproduction in other forums is permitted, provided the original author(s) or licensor are credited and that the original publication in this journal is cited, in accordance with accepted academic practice. No use, distribution or reproduction is permitted which does not comply with these terms. 